\title{
Hybrid predictions of railway induced ground vibration using a combination of experimental measurements and numerical modelling
}

\author{
K.A. Kuo, H. Verbraken ${ }^{1}$, G. Degrande, G. Lombaert \\ Department of Civil Engineering, KU Leuven, Kasteelpark Arenberg 40, Box 2448, 3001 Leuven, Belgium
}

\begin{abstract}
Along with the rapid expansion of urban rail networks comes the need for accurate predictions of railway induced vibration levels at grade and in buildings. Current computational methods for making predictions of railway induced ground vibration rely on simplifying modelling assumptions and require detailed parameter inputs, which lead to high levels of uncertainty. It is possible to mitigate against these issues using a combination of field measurements and state-of-the-art numerical methods, known as a hybrid model. In this paper, two hybrid models are developed, based on the use of separate source and propagation terms that are quantified using in situ measurements or modelling results. These models are implemented using term definitions proposed by the Federal Railroad Administration and assessed using the specific illustration of a surface railway. It is shown that the limitations of numerical and empirical methods can be addressed in a hybrid procedure without compromising prediction accuracy.
\end{abstract}

Keywords:

hybrid modelling, railway induced vibration, vibration transmission

\section{Introduction}

As urban congestion and demand for mass transport increase, new railways are being built in increasingly close proximity to urban areas and building developments are expanding into areas surrounding existing railways. Current and planned rail network expansions include those in Europe (Crossrail in London, Regional Express Network in Brussels, Le Grand Paris Express), China (subway systems, high speed rail network) and the USA (California High Speed Rail). To protect nearby residents and sensitive sites from railway induced ground vibration, limits are set by local and federal authorities. The meeting of these limits requires accurate predictions of railway induced vibration levels.

A number of numerical models for predicting vibration levels in the free field and in buildings have been developed, and involve the application of estimated axle loads to a model of track-soil-structure. These models vary in complexity from simple models used for scoping at an early design phase, to detailed models that are used to assess the need for and design of vibration mitigation measures [1]. The utilised modelling methods include analytical [2], semi-analytical [3, 4] and numerical (finite element (FE) [5], coupled finite element - boundary element (FE-BE) [6], spectral element [7]) formulations. These modelling approaches require detailed knowledge of a large range of material and geometrical parameters, defining the properties of the vehicle, the wheel and rail unevenness, the track and its supporting structure (subgrade or tunnel), the soil, and the building where the vibrations are perceived. These parameters can be identified by dynamic system identification, based on in situ experiments and inverse modelling. The level of confidence in these model predictions is dependent on the uncertainty that exists in both the model structure and the input parameters. Research efforts are focussing on identifying and quantifying these sources of uncertainties

\footnotetext{
Email address: Kirsty.Kuo@kuleuven.be (K.A. Kuo)

${ }^{1}$ Present address: BESIX, Avenue des communautés 100, 1200 Brussels, Belgium Tibration

Published version: K.A. Kuo, H. Verbraken, G. Degrande, and G. Lombaert. Hybrid predictions of railway induced ground vibration using a combination of experimental measurements and numerical modelling. Journal of Sound and Vibration, 373:263-284, 2016. http://dx.doi.org/10.1016/j.jsv.2016.03.007
} 
$[8,9]$. Despite the considerable progress that has been made in developing deterministic forward modelling approaches, an imbalance exists between the effort needed in modelling and parameter estimation and the large prediction uncertainty of numerical models.

The aim of this paper is to explore the application of a hybrid modelling procedure to the problem of railway induced vibration, by using different combinations of numerical analyses and field measurements. This hybrid modelling procedure is developed in response to the dual problems of large prediction uncertainty and significant modelling effort associated with current state-of-the-art railway vibration models. The implementation of the hybrid procedure is illustrated using state-of-the-art numerical models and an extensive field measurement campaign. The development of the hybrid models proceeds here in an incremental manner, with the following two sections setting the context for hybrid model development. Section 2 introduces the case study of a field measurement campaign carried out at Lincent, Belgium; the recorded train passages are used to define measurement uncertainty windows in one third octave bands. Section 3 presents the formulation and results of numerical predictions for the Lincent site, and a comparison with the experimental results. The last three sections present the hybrid model framework, and illustrate it using the measurement data and numerical procedures introduced in Sections 2 and 3, respectively. Section 4 presents an empirical modelling approach, which is then elaborated upon in Section 5 to develop hybrid modelling procedures that are applicable to a variety of scenarios. The results are assessed in Section 6 in conjunction with the in situ measurements and numerical predictions.

\section{Case study: the Lincent site}

\subsection{Site overview}

An extensive field measurement campaign was carried out at a site in Lincent, located on the high speed line L2 between Brussels and Liège [10]. The high-speed line consists of two classical ballasted tracks with continuously welded UIC 60 rails that are supported every $0.60 \mathrm{~m}$ by resilient studded rubber pads on a prestressed monoblock concrete sleeper. Four types of train operate on the line: InterCity (IC) trains of type IC-A and IC-O and the Thalys and ICE high speed trains. The railway line is constructed in an excavation and runs parallel to a highway, separated by an embankment. A cross section of the site is shown in figure 1 .

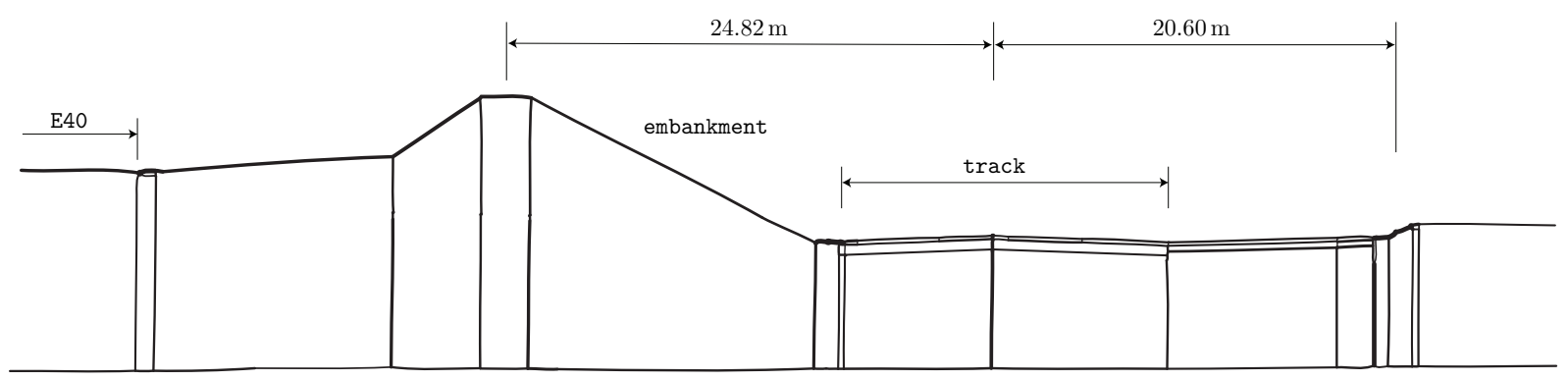

Figure 1: Cross section of the site in Lincent.

\subsection{Experimental setup}

The experimental setup, given in figure 2, involved the installation of sixteen high sensitivity seismic accelerometers (PCB 393 series) measuring free field vertical acceleration along five measurement lines located perpendicular to the track. The data were recorded using a National Instruments PXI-1050 chassis with four 4472B modules. The Nyquist frequency is $500 \mathrm{~Hz}$. During the measurement campaign, high noise levels were recorded below $50 \mathrm{~Hz}$ by the sensors located $8 \mathrm{~m}$ and $16 \mathrm{~m}$ from the track, thus the data from these sensors has been omitted. The free field response during the passage of 103 trains was measured. Of these passages, 16 were IC type trains travelling towards Brussels in a limited speed range of 193-200 km/h. 
The measured vibration velocity level in one-third octave bands of these passages at various distances from the track is shown in figure 3. Close to the track, two peaks are observed in the frequency bands centered on $20 \mathrm{~Hz}$ and $50-63 \mathrm{~Hz}$, which is due resonance of the track on the soil and resonance of the unsprung mass of the axles of the track, respectively. The general trend of vibration attenuation with increasing receiver distance is observed, with stronger attenuation of the higher frequency components, which is a result of both material and geometric damping mechanisms. The influence of train speed cannot be easily determined from the figure, as a change in the train speed might influence both the vibration magnitude and peak frequency, but is estimated to be small within this narrow speed range. The scatter in the results due to the various passages, on the order of 5-10 dB, is primarily attributed to differences in train characteristics, such as the wheel unevenness and axle loads.

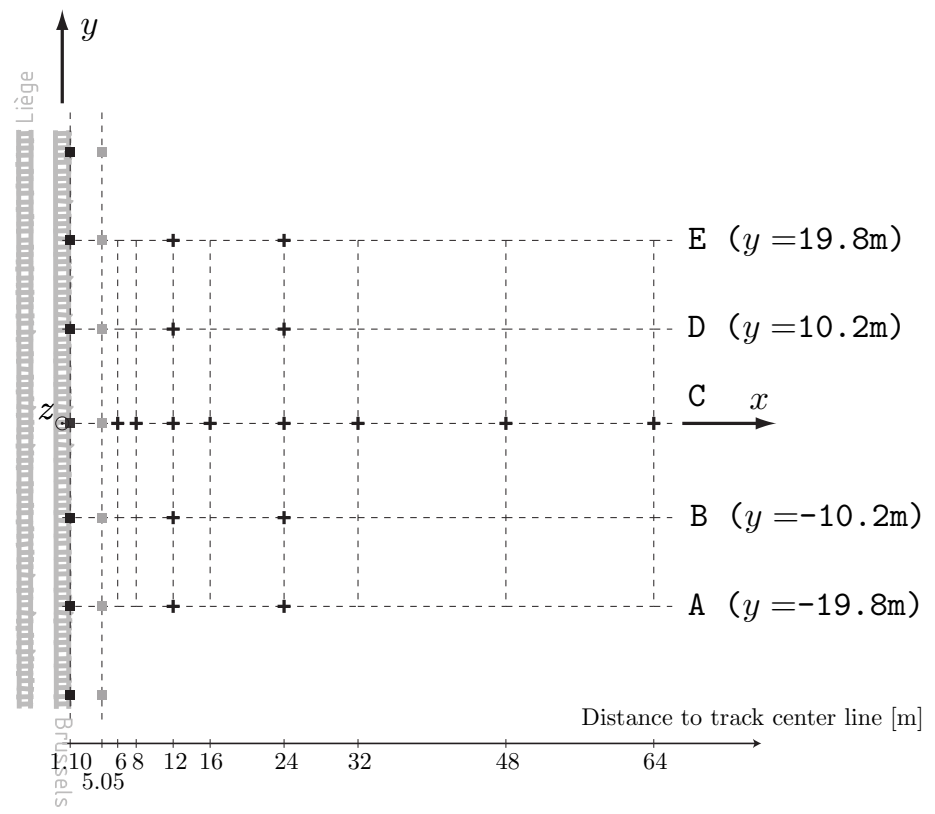

Figure 2: Measurement setup in the free field at the site in Lincent, indicating the receiver points (廿) and the source points

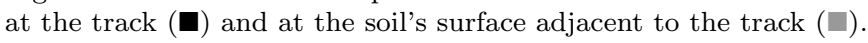

Of the sixteen accelerometers installed at the ground surface, five receivers are located at $12 \mathrm{~m}$ from the track, and another five at $24 \mathrm{~m}$ from the track, with each pair of adjacent receivers offset by a longitudinal distance of approximately $10 \mathrm{~m}$. Figure 4 shows the variation in vibration velocity levels for four train passages of various speeds using the data from these adjacent receivers. The variation between adjacent receivers, of the order of $0-5 \mathrm{~dB}$, is expected to be primarily due to differences in local soil characteristics and installation of the measurement equipment, with wheel-rail unevenness and variation in the track accounting for some (smaller) effect.

By collating the data from each of the 16 train passages, an average vibration velocity level can be determined, together with the upper and lower data bounds that represent a measurement uncertainty window, shown in figure 5. The inclusion of data from adjacent receivers results in a wider uncertainty window for the receivers at $12 \mathrm{~m}$ and $24 \mathrm{~m}$ from the track. From this figure, it can be proposed that a 5$15 \mathrm{~dB}$ uncertainty level exists on vibration velocity levels measured during a train passage at the Lincent site. Whether this uncertainty value can reasonably be extrapolated to other sites has not yet been established. 


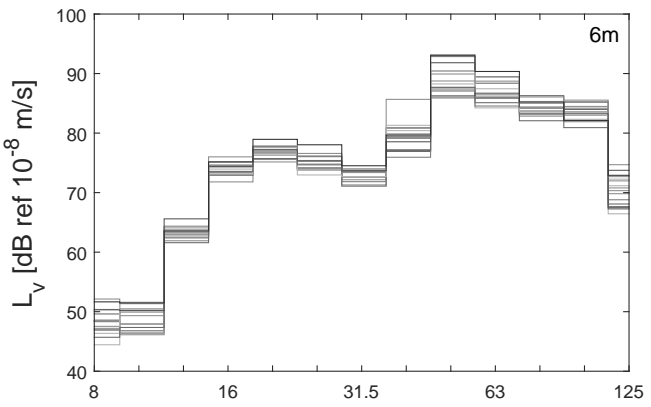

(a)

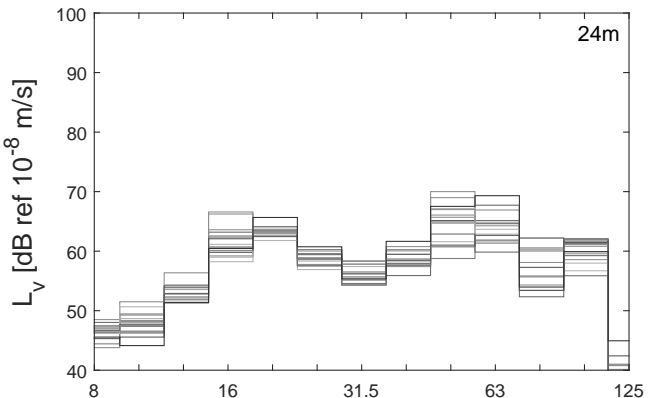

(c)

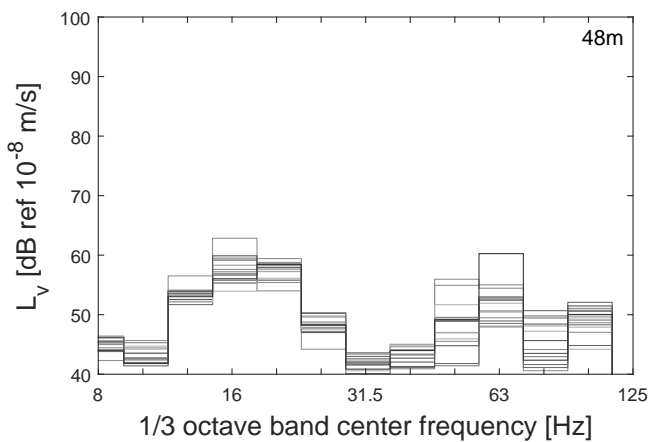

(b)
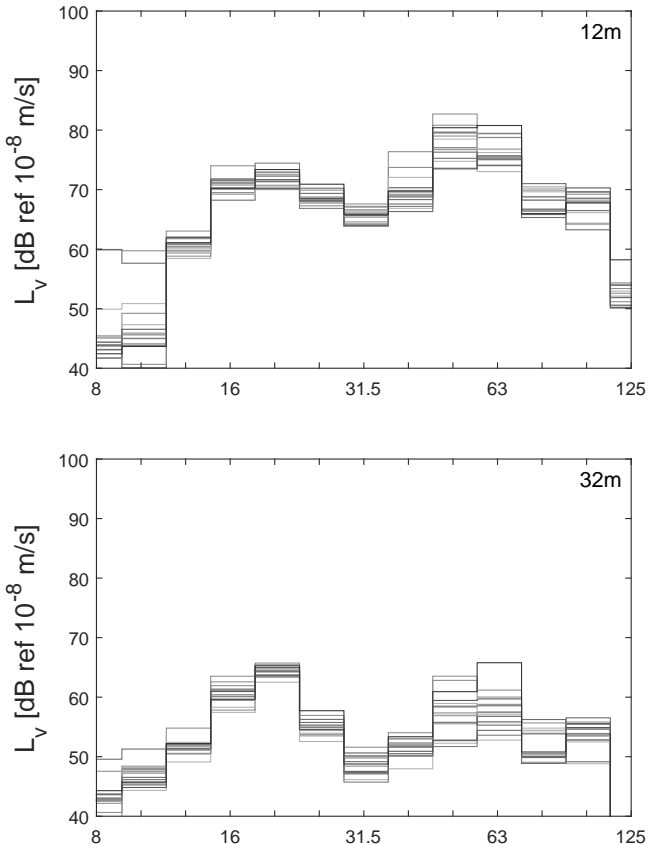

(d)

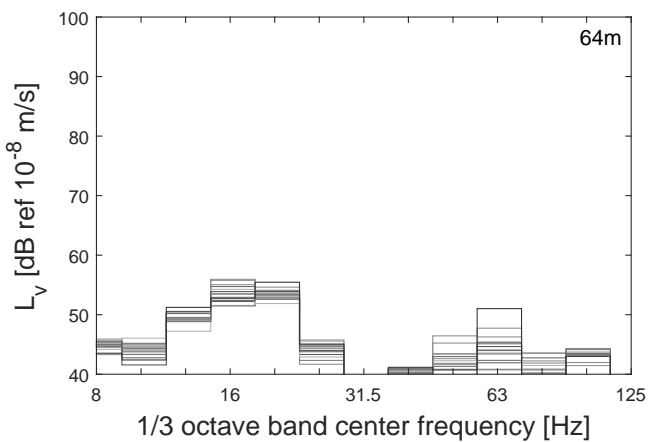

Figure 3: One-third octave band RMS level of the measured vertical free field velocity at line C $(y=0 \mathrm{~m})$ at (a) $6 \mathrm{~m},(\mathrm{~b}) 12 \mathrm{~m}$, (c) $24 \mathrm{~m}$, (d) $32 \mathrm{~m}$, (e) $48 \mathrm{~m}$, and (f) $64 \mathrm{~m}$ from the track center line during the passage of $16 \mathrm{IC}$ trains $(193-200 \mathrm{~km} / \mathrm{h})$. The train speed is indicated by the greyscale, where a darker shade indicates a higher speed. 

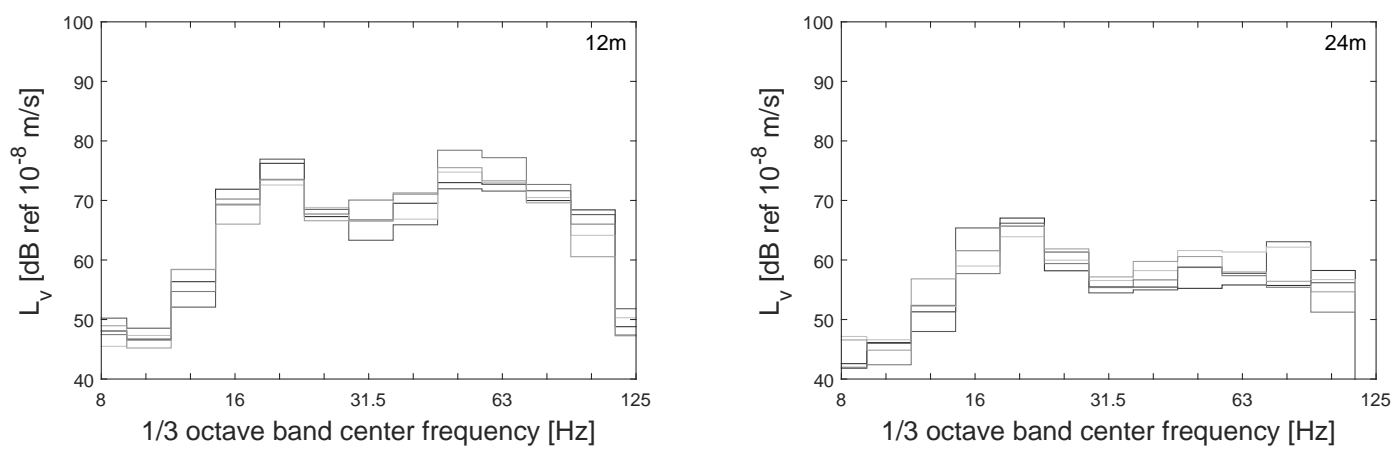

(a)
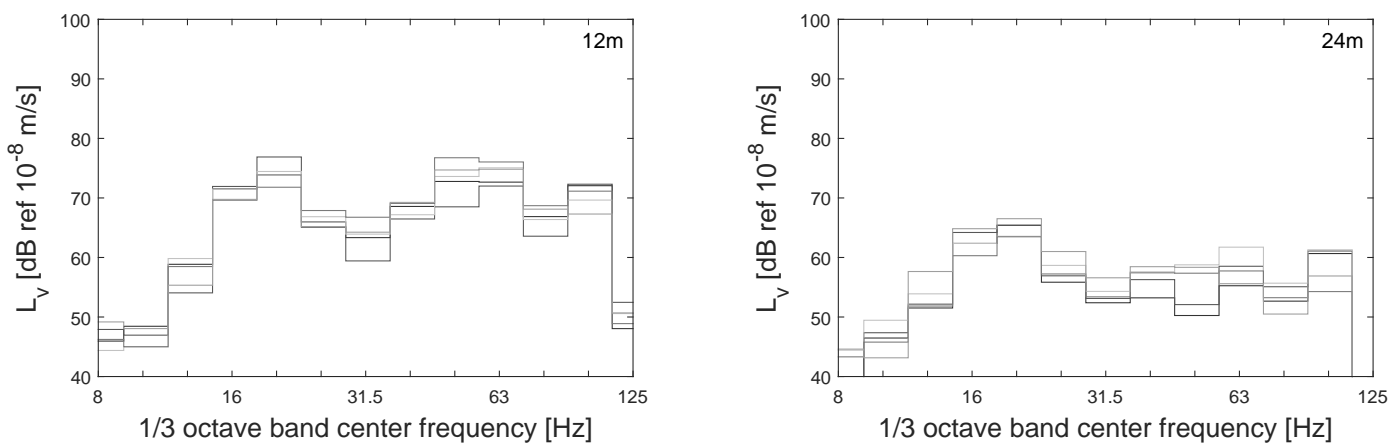

(b)
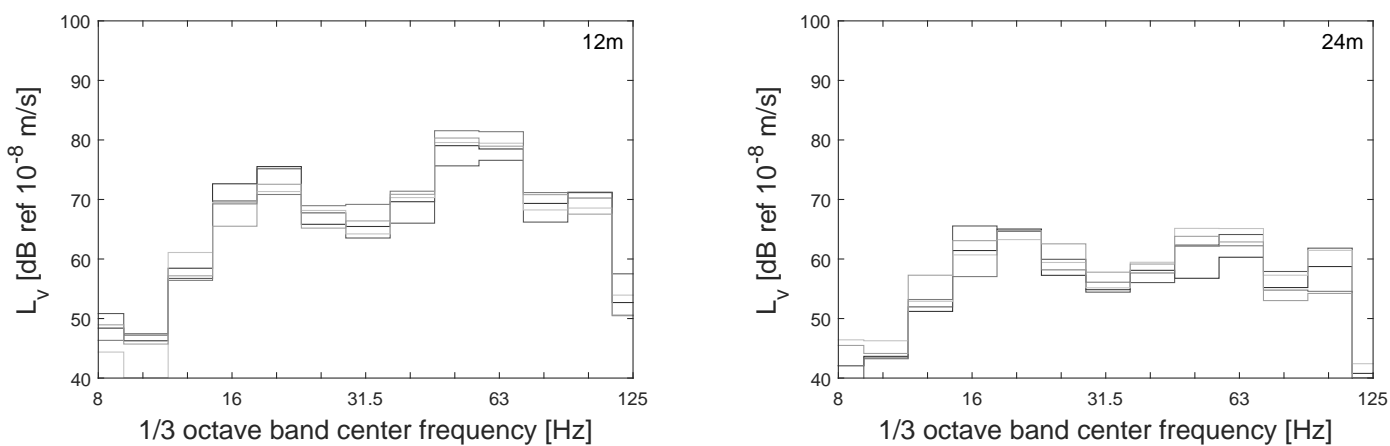

(c)
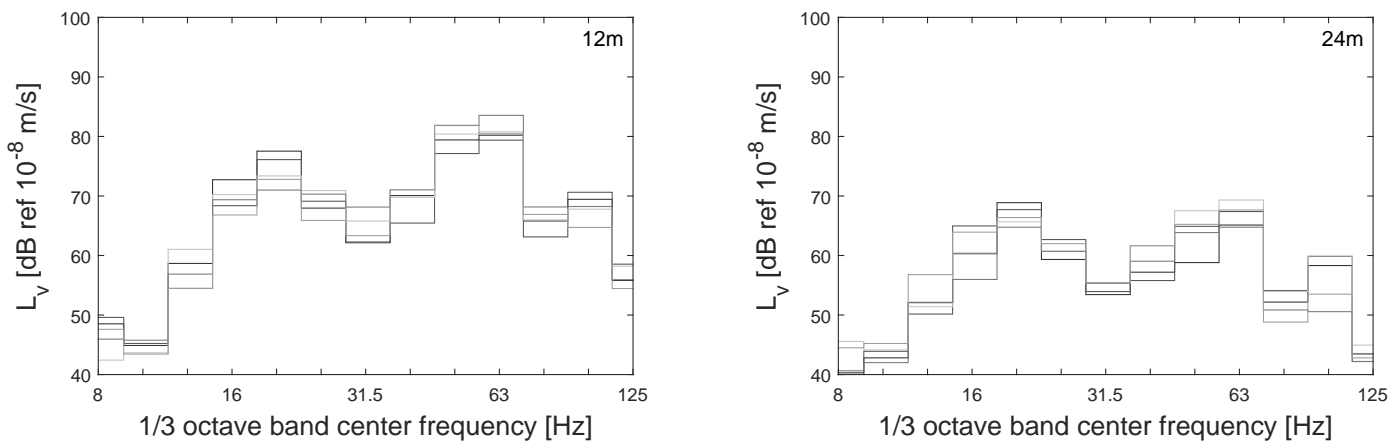

figure 4: One-third octave band RMS level of the measured vertical free field velocity along the five measurement lines at distances of $12 \mathrm{~m}$ (left) and $24 \mathrm{~m}$ (right) for IC type train passages at (a) $193 \mathrm{~km} / \mathrm{h}$, (b) $196 \mathrm{~km} / \mathrm{h}$, (c) $198 \mathrm{~km} / \mathrm{h}$, and (d) $200 \mathrm{~km} / \mathrm{h}$. The $y$-coordinate is indicated by the grayscale, where a darker shade indicates a smaller $y$-coordinate. 


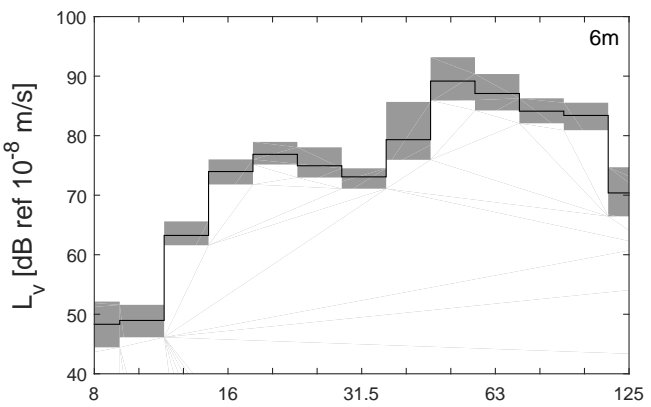

(a)

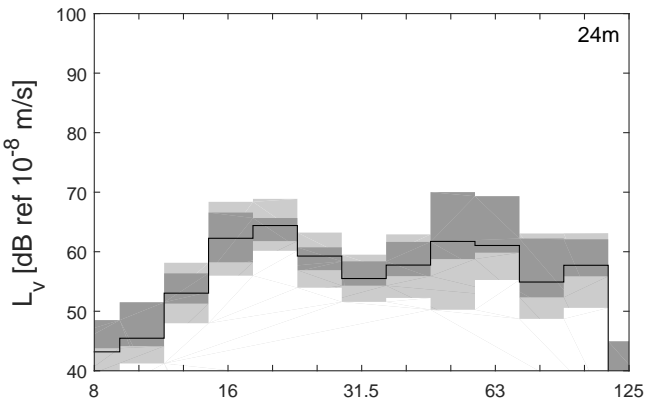

(c)

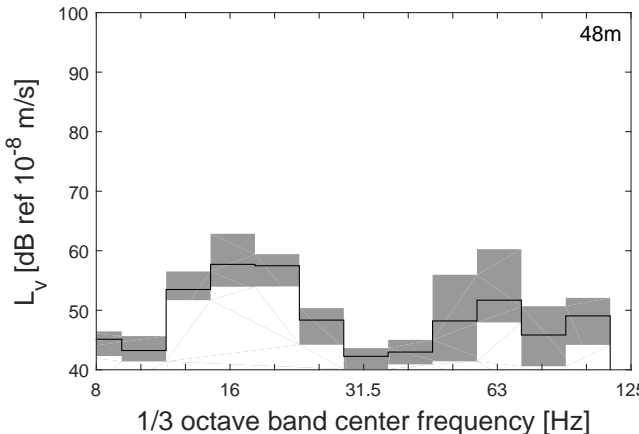

(b)
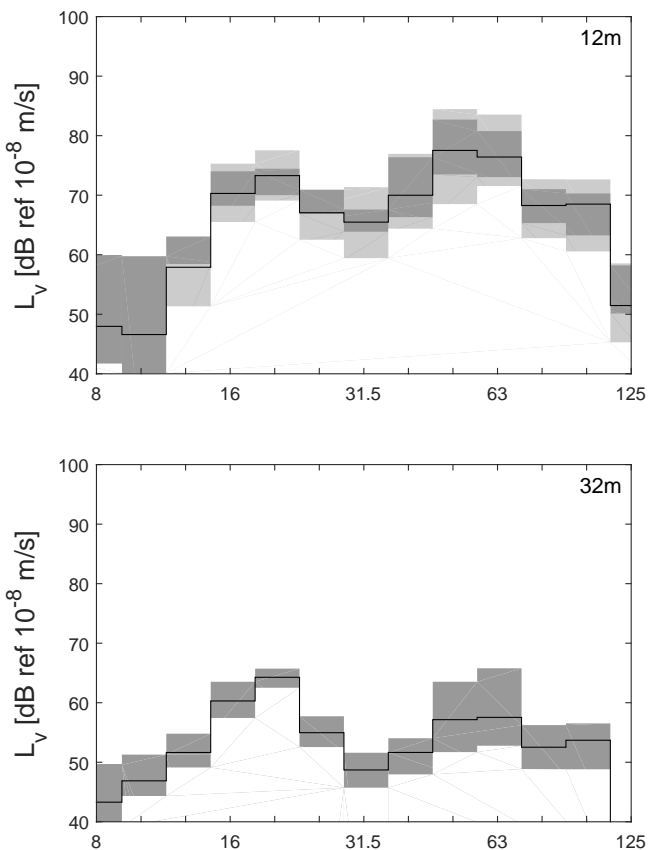

(d)

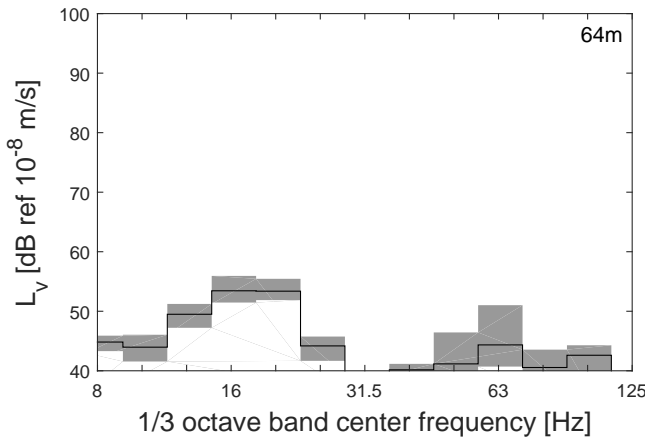

Figure 5: The average one-third octave band RMS level of the measured vertical free field velocities at (a) $6 \mathrm{~m}$, (b) $12 \mathrm{~m}$, (c) $24 \mathrm{~m}$, (d) $32 \mathrm{~m}$, (e) $48 \mathrm{~m}$, and (f) $64 \mathrm{~m}$ from the track center line during the passage of $16 \mathrm{IC}$ trains $(193-200 \mathrm{~km} / \mathrm{h})$. The upper and lower measurement bounds define the shaded region. The results at $12 \mathrm{~m}$ and $24 \mathrm{~m}$ include data from adjacent receiver locations, indicated by the lighter shaded region. 


\section{Making predictions: numerical methods}

\subsection{General framework}

Railway induced vibrations are generated by time-varying axle loads $g_{k}(t)$ at each axle $k$. These axle loads are made up of quasi-static $\left(g_{\mathrm{s} k}\right)$ and dynamic $\left(g_{\mathrm{d} k}(t)\right)$ contributions:

$$
g_{k}(t)=g_{\mathrm{s} k}+g_{\mathrm{d} k}(t)
$$

The former are the result of the total weight of the train being distributed over each of the axles. The latter are due to several mechanisms such as wheel and rail unevenness, impact excitation due to rail joints, wheel flats, switches and crossings, and parametric excitation due to sleeper periodicity [11]. These loads are transferred to the track, its supporting structure (ballast, subgrade, slab or tunnel) and the soil, where vibrations propagate as elastic waves. These waves excite nearby buildings through their foundations, resulting in structural vibration and re-radiated noise.

Numerical prediction models usually involve a two-step procedure where the dynamic vehicle loads are computed in a first step and then applied to the track for calculation of the free field response in a second step [12]. For example, by assuming perfect contact between the track and the train and a longitudinally invariant track geometry [13], the dynamic axle loads $\hat{\mathbf{g}}_{\mathrm{d}}(\omega)$ can be related to the combined wheel and rail

unevenness $\hat{\mathbf{u}}_{\mathrm{w} / \mathrm{r}}(\omega)$ perceived by the axles through the track and vehicle compliance matrices $\hat{\mathbf{C}}^{\mathrm{t}}(\omega)$ and $\hat{\mathbf{C}}^{\mathrm{v}}(\omega)$, where $\omega$ is the angular frequency. This results in:

$$
\left[\hat{\mathbf{C}}^{\mathrm{t}}(\omega)+\hat{\mathbf{C}}^{\mathrm{v}}(\omega)\right] \hat{\mathbf{g}}_{\mathrm{d}}(\omega)=-\hat{\mathbf{u}}_{\mathrm{w} / \mathrm{r}}(\omega)
$$

The second step in the numerical procedure involves the application of the dynamic axle loads to the track and determination of the free field response $u\left(\mathbf{x}^{\prime}, t\right)$. When a transfer function $H_{\mathrm{ts}}\left(\mathbf{x}_{k}, \mathbf{x}^{\prime}, t\right)$ is available that relates the response at a point in the free field $\mathbf{x}^{\prime}$ to the load at a point $\mathbf{x}_{k}$ on the track, this can be formally written as:

$$
u\left(\mathbf{x}^{\prime}, t\right)=\sum_{k=1}^{n_{\mathrm{a}}} \int_{-\infty}^{t} H_{\mathrm{ts}}\left(\mathbf{x}_{k}(\tau), \mathbf{x}^{\prime}, t-\tau\right) g_{k}(\tau) d \tau
$$

where $n_{\mathrm{a}}$ is the total number of axles [12].

\subsection{Model implementation}

The general model framework is implemented here using a coupled 2.5D FE-BE model [10] that offers a balance between computational cost and model complexity, by assuming that the site topography shown in figure 1 can be represented by a horizontally layered halfspace. Figure 6(a) shows the numerical model used to solve the track-soil interaction problem, which consists of the track, modelled using a 2.5D FE methodology, coupled to the soil, represented by a horizontally layered halfspace modelled using a 2.5D BE approach. The track submodel includes rails, modelled as Euler-Bernoulli beams; rail pads and sleepers, represented as continuous spring-damper connections to a uniformly distributed mass; and a ballast layer, modelled as elastic media using solid elements. The soil submodel uses boundary elements along the tracksoil interface. For the Lincent site conditions, the track receptance is primarily influenced by the underlying soil stratification, which means that explicit modelling of the excavation and the track subgrade can be avoided [10]. The fundamental solutions of the layered halfspace are provided by the Green's functions that represent the displacement in the soil domain due to an impulsive load, and are calculated using the direct stiffness method, implemented in the MATLAB toolbox EDT [14]. The track compliance matrix is calculated in a frame of reference that moves with the train and represents the track response at each axle position due to dynamic loads applied at each axle. The vehicle compliance matrix is calculated using the simplified vehicle model shown in figure $6(\mathrm{~b})$, that accounts for the unsprung mass of the wheel set and uses a Hertzian spring to model the contact between the wheel set and both rails. Having determined the two compliance matrices and using the measured wheel and rail unevenness profile from the site investigation, the dynamic axle loads can be computed using equation (2). 

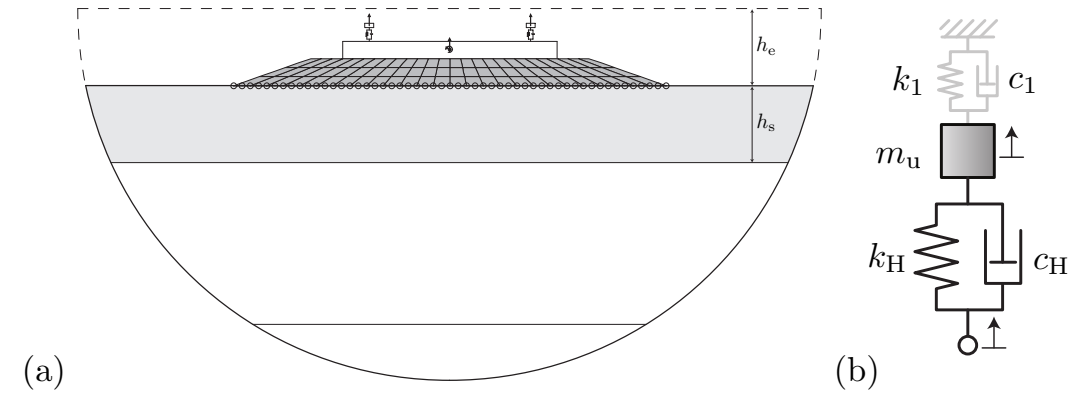

Figure 6: (a) Cross section of the 2.5D track-soil model used for calculating the track compliance, where $h_{\mathrm{e}}$ indicates the depth of the excavation and $h_{\mathrm{s}}$ indicates the depth of the track subgrade, and (b) the simplified vehicle model.

The transfer function is determined using the 2.5D coupled FE-BE model shown in figure 7. An excitation force is applied at position $\mathbf{x}_{k}$ to the FE track submodel. The resulting displacements and tractions at the track-soil interface are used as inputs in the BE soil submodel, which is used to determine the response in the free field and thus the transfer function. As the excavation and the track subgrade have been shown to have a small but non-negligible influence on the track-free field mobility [10], they are included in this model.

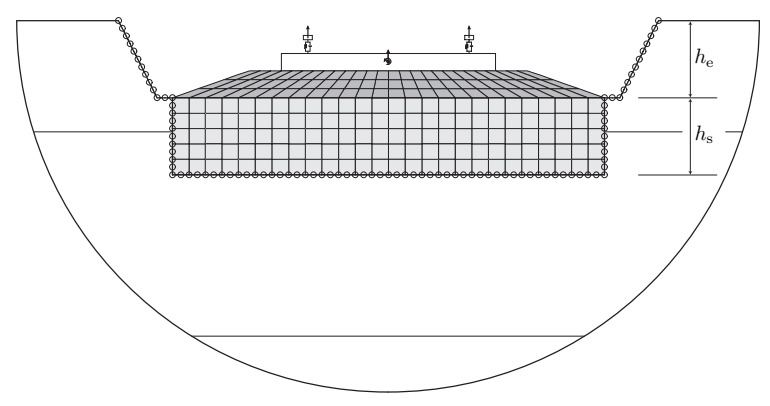

Figure 7: Cross section of the 2.5D track-soil model used for calculating the track-free field transfer functions.

\subsection{Parameter determination - site characteristics}

Sample borings and CPT tests showed that the Lincent soil profile consists of a shallow top layer of silt, followed by a layer of fine sand. Below this, a sequence of hard arenite layers embedded in clay is followed by a sequence of fine sand and clay layers. The small strain dynamic soil characteristics are determined from the results of two seismic cone penetration tests and two spectral analysis of surface waves tests [15, 16]. For each layer, the depth $h$, shear wave velocity $C_{\mathrm{s}}$, dilatational wave velocity $C_{\mathrm{p}}$, material damping ratios $\beta_{\mathrm{s}}$ and $\beta_{\mathrm{p}}$ in shear and dilatational deformation, and density $\rho$ are summarised in table 1.

The dynamic track characteristics are determined based on design values or identified using the measured track response. Lombaert et al. [17] measured track receptances at the site by applying a hammer impact at the rail head, while using accelerometers mounted on the rail to measure the corresponding rail response in both loaded and unloaded conditions. The input parameters of a 2.5D FE-BE model were then determined indirectly by fitting the predicted track receptance to the measured result. These input parameters are used by Verbraken [10] as initial estimates in a 2.5D FE-BE model that has been modified to take into account the excavation and the track subgrade. Parameter updating is again performed by fitting the model output to the measured track receptances. The identified dynamic track charateristics are summarised in table 2 . 


\begin{tabular}{ccccccc}
\hline Layer & $\begin{array}{c}h \\
{[\mathrm{~m}]}\end{array}$ & $\begin{array}{c}C_{\mathrm{s}} \\
{[\mathrm{m} / \mathrm{s}]}\end{array}$ & $\begin{array}{c}C_{\mathrm{p}} \\
{[\mathrm{m} / \mathrm{s}]}\end{array}$ & $\begin{array}{c}\beta_{\mathrm{s}} \\
{[-]}\end{array}$ & $\begin{array}{c}\beta_{\mathrm{p}} \\
{[-]}\end{array}$ & $\begin{array}{c}\rho \\
{\left[\mathrm{kg} / \mathrm{m}^{3}\right]}\end{array}$ \\
\hline 1 & 1.4 & 128 & 286 & 0.044 & 0.044 & 1800 \\
2 & 2.7 & 176 & 286 & 0.038 & 0.038 & 1800 \\
3 & $\infty$ & 355 & 1667 & 0.037 & 0.037 & 1800 \\
\hline
\end{tabular}

Table 1: Dynamic soil characteristics for the site in Lincent, Belgium.

The EM130 measurement vehicle, equipped with an Applanix POS/TG system, was used to record the irregularity and alignment of both rails, and the curvature, superelevation and grade of the Lincent track. Reliable measurements of the track unevenness were obtained in a wavelength range of 3 to $63 \mathrm{~m}$, which corresponds to an excitation in the frequency range of 0.9 to $17 \mathrm{~Hz}$ at a train speed of $198 \mathrm{~km} / \mathrm{h}$. The PSD of the average measured vertical unevenness of both rails is shown in figure 8. To obtain estimates for the unevenness at smaller wavelengths, the measured PSD was fitted to a typical rail unevenness profile $\tilde{S}_{u_{\mathrm{w} / \mathrm{r} z}}\left(k_{y}\right)\left[\mathrm{m}^{3} / \mathrm{rad}\right]$ proposed by the FRA [18]:

$$
\tilde{S}_{u_{\mathrm{w} / \mathrm{r} z}}\left(k_{y}\right)=\frac{1}{2 \pi} A \frac{n_{y 2}^{2}\left(n_{y}^{2}+n_{y 2}^{2}\right)}{n_{y}^{4}\left(n_{y}^{2}+n_{y 1}^{2}\right)}
$$

where $n_{y}=k_{y} / 2 \pi$ is the circumferential wavenumber and the constants $n_{y 1}=0.0233 \mathrm{~m}^{-1}$ and $n_{y 2}=$ $0.13 \mathrm{~m}^{-1}$ are determined based on a database. The parameter $A$ represents the quality of the track. The FRA defines six classes of unevenness, of which the limiting class 1 and class 6 are shown in figure 8 . The fitted Lincent unevenness (also shown in figure 8) has $A=4.75 \times 10^{-9}$, and is much lower than the FRA classes of unevenness, indicating low roughness and very good track quality.

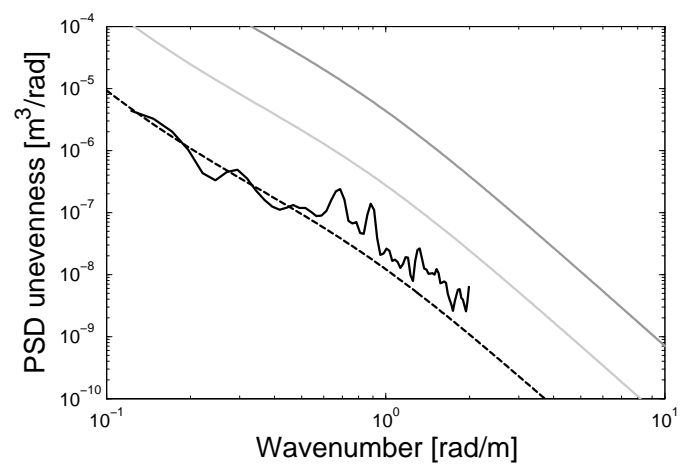

Figure 8: Measured (solid black line) and fitted (dashed black line) PSD of the vertical rail unevenness at the site in Lincent. Also shown are FRA unevenness profiles class 1 (dark grey line) and class 6 (light grey line).

\subsection{Results}

Using the determined parameters and the two-step numerical formulation, results are obtained for the vibration velocity levels at various distances from the track for an IC train travelling at $198 \mathrm{~km} / \mathrm{h}$. These are shown in figure 9 . The numerical predictions are overlaid on experimental measurements shown in figure 5. The agreement between the model predictions and the measured results is moderately good in the $25-100 \mathrm{~Hz}$ region, with the prediction generally lying within $0-5 \mathrm{~dB}$ from the shaded measurement bounds. Less good agreement is observed at frequencies below $25 \mathrm{~Hz}$, with discrepancies of up to $10 \mathrm{~dB}$. Despite this, and in light of the significant levels of uncertainty that have been shown to be present in numerical models [19], it can be concluded that this numerical method has produced credible vibration predictions for the Lincent site. This is attributed to the fact that the site at Lincent has been specially selected for model validation 


\begin{tabular}{lll}
\hline Rail & Flexural stiffness (per rail) & $E_{\mathrm{r}} I_{\mathrm{r}}=6.45 \times 10^{6} \mathrm{Nm}^{2}$ \\
& Mass per length (per rail) & $\rho_{\mathrm{r}} A_{\mathrm{r}}=60.3 \mathrm{~kg} / \mathrm{m}$ \\
& Position of left rail & $x_{\mathrm{r} 1}=-0.7175 \mathrm{~m}$ \\
& Position of right rail & $x_{\mathrm{r} 2}=+0.7175 \mathrm{~m}$ \\
\hline Rail pad & Stiffness & $\bar{k}_{\mathrm{rp}}=255.7 \times 10^{6} \mathrm{~N} / \mathrm{m}^{2}$ \\
& Viscous damping & $\bar{c}_{\mathrm{rp}}=22.5 \times 10^{3} \mathrm{Ns} / \mathrm{m}^{2}$ \\
\hline Sleeper & Mass per length & $\bar{m}_{\mathrm{sl}}=500 \mathrm{~kg} / \mathrm{m}$ \\
& Mass moment of inertia & $\rho_{\mathrm{sl}} \bar{I}_{\mathrm{tsl}}=262.17 \mathrm{kgm}$ \\
& Length & $l_{\mathrm{sl}}=2.50 \mathrm{~m}$ \\
\hline Ballast & Height & $h_{\mathrm{b}}=0.35 \mathrm{~m}$ \\
& Upper width & $w_{\mathrm{bu}}=3.60 \mathrm{~m}$ \\
& Lower width & $w_{\mathrm{bl}}=5.60 \mathrm{~m}$ \\
& Shear wave velocity & $C_{\mathrm{s}}=153.7 \mathrm{~m} / \mathrm{s}$ \\
& Longitudinal wave velocity & $C_{\mathrm{p}}=307.4 \mathrm{~m} / \mathrm{s}$ \\
& Shear damping ratio & $\beta_{\mathrm{s}}=0.03$ \\
& Longitudinal damping ratio & $\beta_{\mathrm{p}}=0.03$ \\
& Mass density & $\rho_{\mathrm{b}}=1700 \mathrm{~kg} / \mathrm{m}^{3}$ \\
\hline Track subgrade & Shear wave velocity & $C_{\mathrm{s}}=300 \mathrm{~m} / \mathrm{s}$ \\
& Longitudinal wave velocity & $C_{\mathrm{p}}=600 \mathrm{~m} / \mathrm{s}$ \\
& Shear damping ratio & $\beta_{\mathrm{s}}=0.044$ \\
& Longitudinal damping ratio & $\beta_{\mathrm{p}}=0.044$ \\
& Mass density & $\rho_{\mathrm{s}}=1854 \mathrm{~kg} / \mathrm{m}^{3}$ \\
& Height & $h_{\mathrm{s}}=1 \mathrm{~m}$ \\
\hline
\end{tabular}

Table 2: Dynamic characteristics of the ballasted track at the site in Lincent after updating of the track receptance.

purposes, due to its relatively flat site topography and lack of surrounding buildings making it ideal for incorporation into numerical models. Furthermore, extensive testing efforts have provided detailed data on the site parameters for use in the numerical models. 


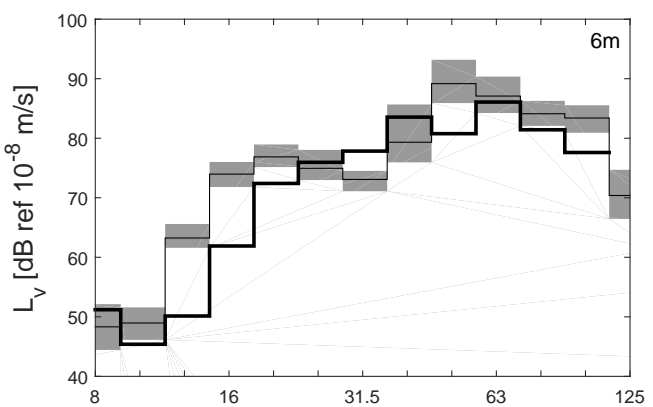

(a)

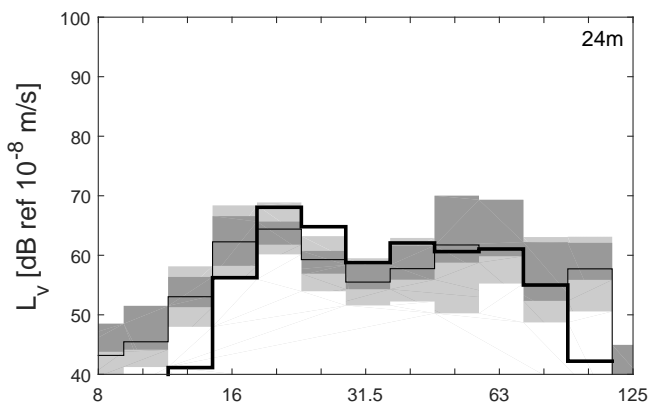

(c)

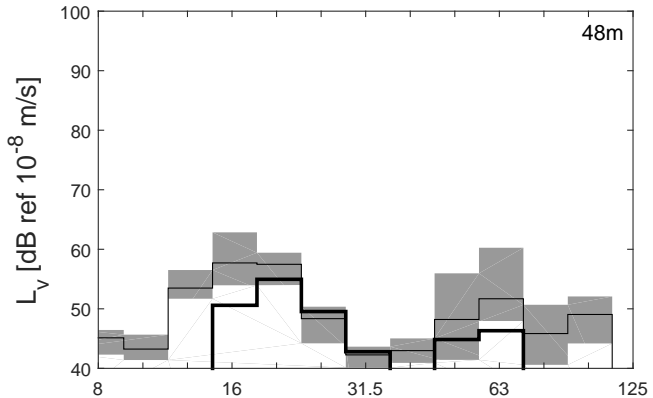

(e)

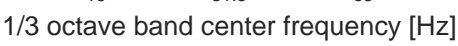

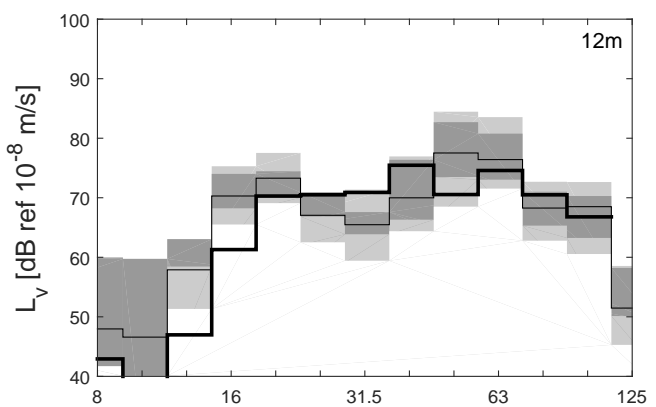

(b)

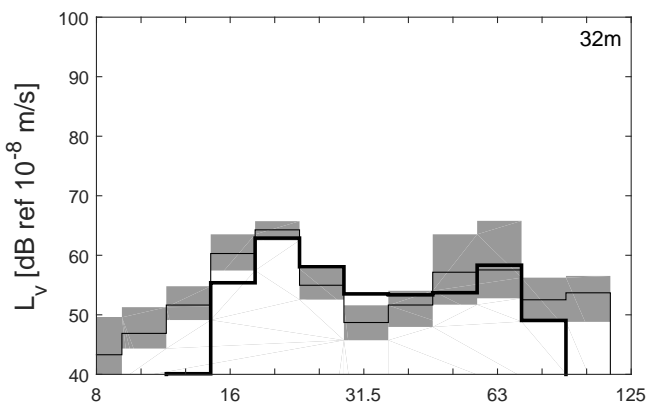

(d)

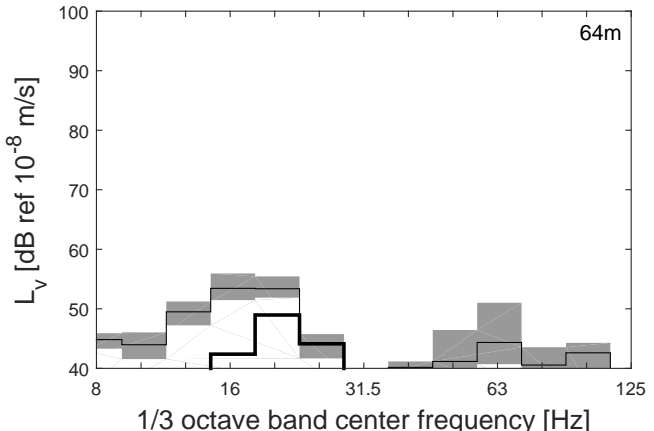

Figure 9: The numerical prediction (thick black line) of the one-third octave band RMS level of the measured vertical free field velocities at (a) $6 \mathrm{~m}$, (b) $12 \mathrm{~m}$, (c) $24 \mathrm{~m}$, (d) $32 \mathrm{~m}$, (e) $48 \mathrm{~m}$, and (f) $64 \mathrm{~m}$ from the track center line for an IC train $(198 \mathrm{~km} / \mathrm{h}$ ). Underlain is the average (thin black line), upper and lower measurement bounds determined from experimental measurements of 16 IC trains $(193-200 \mathrm{~km} / \mathrm{h})$. The bounds at $12 \mathrm{~m}$ and $24 \mathrm{~m}$ include data from adjacent receiver locations, indicated by the lighter shaded region. 


\section{Making predictions: empirical methods}

\subsection{Division of vibration terms}

In practice, vibration predictions are made using simplified empirical methods. Examples of empirical methods include the procedures developed by the FRA and the Federal Transit Administration (FTA) of the U.S. Department of Transportation [1, 20], the Swiss Federal Railways (SBB) [21], Madshus et al. [22], and Hood et al. [23]. Following the guidance of the ISO 14837-1 standard [24], the procedures developed by the FRA and FTA involve three different levels of assessment: a screening procedure, a general environmental assessment, and a detailed vibration analysis. The first two levels are used to screen for vibration sensitive sites. The third level uses field measurements of excitation forces and transmission paths to estimate the ground response, to which adjustment factors are applied for calculation of the building response [25, 26]. The advantage of this method is that it avoids the need for extensive soil characterisation tests by directly measuring the vibration transmission through the soil [1].

The ISO 14837-1 standard recommends a general framework that involves expressing the magnitude of the quasi-stationary response $A(f)$ in the free field during a train passage as the sum of two terms:

$$
A(f)=S(f)+P(f)
$$

where $S(f)$ represents the source strength and $P(f)$ characterises the propagation path. All three terms are expressed in decibels, as a function of frequency $f$. The source and propagation terms can be considered to be uncoupled only in some situations for simplified models. To obtain the vibration velocity level at a given frequency, each of these terms should be calculated at the same frequency, which is strictly speaking not valid for moving sources due to the Doppler effect [10].

\subsection{Model implementation}

The empirical procedure proposed by the FRA [1] is a popular approach that conforms to this general framework, and is presented here as an example of an empirical method that uses division of source and receiver terms. The vibration transfer from track to ground surface is divided into two components: excitation force and vibration propagation. This is expressed in the equation:

$$
\mathrm{L}_{\mathrm{v}}\left(\mathbf{x}^{\prime}\right)=\mathrm{L}_{\mathrm{F}}\left(\mathbf{X}, \mathbf{x}^{\prime}\right)+\mathrm{TM}_{\mathrm{L}}\left(\mathbf{X}, \mathbf{x}^{\prime}\right)
$$

where $\mathbf{X}$ is a vector that collects all the source points, located on the rail heads, that are used for the field measurements. The term $\mathrm{L}_{\mathrm{v}}\left(\mathbf{x}^{\prime}\right)$ is the vibration velocity level at the receiver point $\mathbf{x}^{\prime}$, and is measured in decibels at one-third octave band intervals. The excitation force, represented by the equivalent force density level $\mathrm{L}_{\mathrm{F}}\left(\mathbf{X}, \mathbf{x}^{\prime}\right)$, depends on both the actual force generated at the wheel/rail interface and the dynamic characteristics of the transit structure (that is, the tunnel or ballast and the soil). The vibration propagation from the track, through the soil to the receiver point on the soil surface is contained within the line source transfer mobility term $\mathrm{TM}_{\mathrm{L}}\left(\mathbf{X}, \mathbf{x}^{\prime}\right)$.

The FRA procedure is applicable to both existing and new build situations, and its implementation for the case of a new railway is illustrated in figure 10 and described here. Firstly, the line source transfer mobility $\mathrm{TM}_{\mathrm{L}}\left(\mathbf{X}_{1}, \mathbf{x}^{\prime}\right)$ is measured directly at the site of the new railway (the 'assessment site' - figure 10a). As the new railway has not yet been built, source points $\mathbf{X}$ at the rail heads are not available, so source points $\mathbf{X}_{1}$ located on the soil's surface close to the future track position are used. The line source transfer mobility is obtained as the superposition of the point source transfer mobility levels $\operatorname{TM}_{\mathrm{P}}\left(\mathbf{x}_{1 k}, \mathbf{x}^{\prime}\right)$ for a series of $n$ equidistant source points with spacing $h$ :

$$
\mathrm{TM}_{\mathrm{L}}\left(\mathbf{X}_{1}, \mathbf{x}^{\prime}\right)=10 \log _{10}\left[h \sum_{k=1}^{n} 10^{\frac{\mathrm{TM}_{\mathrm{P}}\left(\mathbf{x}_{1 k}, \mathbf{x}^{\prime}\right)}{10}}\right]
$$

The absence of a track at the assessment site means that it is not possible to measure the force density level directly, so it is extrapolated from measurements of a similar train passage at a second site with similar 


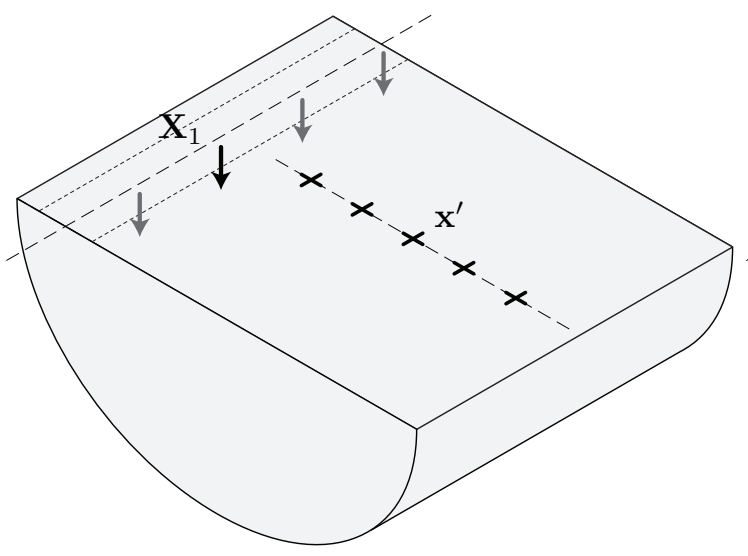

(a)

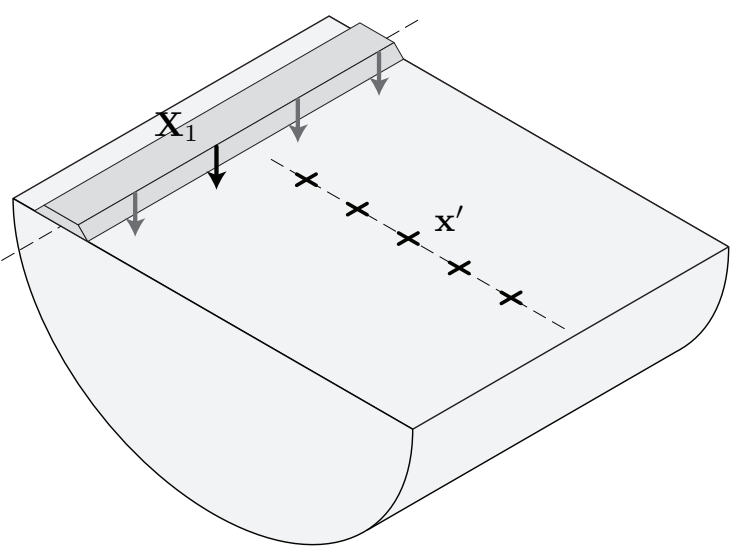

(b)

Figure 10: Position of the source and receiver points at (a) the assessment site, where the new railway is to be built and (b) the reference site.

track and soil characteristics (the 'reference site' - figure 10b). At this reference site, the force density level is calculated as the difference between the measured vibration velocity level $\mathrm{L}_{\mathrm{v}}\left(\mathbf{x}^{\prime}\right)$ and the line source transfer mobility level $\mathrm{TM}_{\mathrm{L}}\left(\mathbf{X}_{1}, \mathbf{x}^{\prime}\right)$, which for consistency is measured using the same source locations $\mathbf{X}_{1}$, located on the soil's surface next to the track, and receiver locations $\mathbf{x}^{\prime}$ as the assessment site. The resulting force density level:

$$
\mathrm{L}_{\mathrm{F}}\left(\mathbf{X}_{1}, \mathbf{x}^{\prime}\right)=\mathrm{L}_{\mathrm{v}}\left(\mathbf{x}^{\prime}\right)-\mathrm{TM}_{\mathrm{L}}\left(\mathbf{X}_{1}, \mathbf{x}^{\prime}\right)
$$

represents the equivalent fixed line source that results in the same vibration velocity level as the train passage. Vibration predictions at the assessment site are then calculated as the sum of the estimated force density level from the reference site and the transfer mobility measured at the assessment site.

\subsection{Results}

The line source transfer mobilities and force density terms for the site at Lincent were determined using the recorded train passages and measured transfer functions, and are presented below.

Transfer functions were obtained using an impact hammer with a mass of $5.5 \mathrm{~kg}$ and a soft tip equipped with a force sensor (PCB 086D50). Two impact locations, the edge of the sleeper and an aluminium foundation installed at the soil's surface at a distance of $5.05 \mathrm{~m}$ from the centre of the track were used. The free field response was obtained by summing the acceleration time signals for 100 hammer impacts at each impact location, then windowing and integrating to obtain the velocity response. An averaged mobility between each source and receiver could then be computed using the forcing history. The hammer impacts were applied every $10 \mathrm{~m}$ along the track, over a distance of $160 \mathrm{~m}$. The line source transfer mobility were then determined as the summation of the point source transfer mobilities according to equation (7). Figure 11 shows the measured line source transfer mobilities determined at distances of $6 \mathrm{~m}, 12 \mathrm{~m}, 24 \mathrm{~m}$, $32 \mathrm{~m}, 48 \mathrm{~m}$ and $64 \mathrm{~m}$ from the track. The receiver locations were fixed regardless of the impact location, so there is a smaller source-receiver distance when impacts are applied at the foundation on the soil's surface adjacent to the track. This explains the large magnitude of the line source transfer mobility at $6 \mathrm{~m}$ in figure 11(b). Apart from this distance effect, the line source transfer mobilities obtained using impacts on the track are slightly lower than those obtained using impacts adjacent to the track due to a vibration filtering effect caused by the presence of the track. The transfer functions show a non-uniform decay with increasing distance from the track, due to a combined effect of geometrical spreading and material damping in the soil. As the attenuation is stronger for higher frequencies, the peak of the frequency content is shifted towards lower frequencies. 


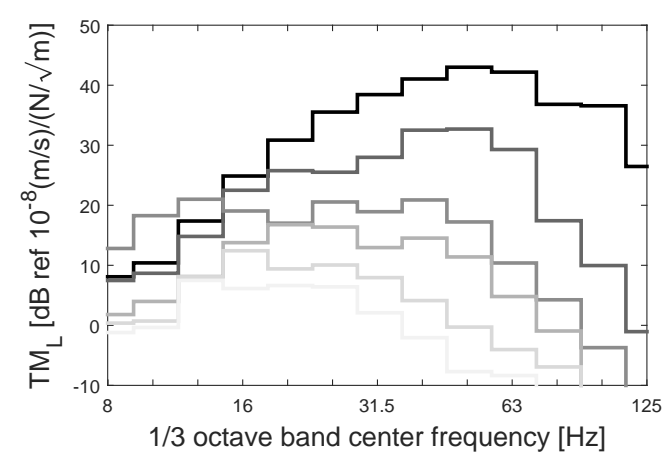

(a)

Figure 11: Measured line source transfer mobility level for source points at (a) the edge of the sleeper and (b) the soil's surface adjacent to the track, for receivers at $6 \mathrm{~m}, 12 \mathrm{~m}, 24 \mathrm{~m}, 32 \mathrm{~m}, 48 \mathrm{~m}$, and $64 \mathrm{~m}$. The distance from the track is indicated by the line shade, where a darker shade indicates a smaller distance.

The measured force density level is determined as the difference between the vibration velocity level for a given train passage and the measured line source transfer mobilities shown in figure 11. A single passage of an IC train at $198 \mathrm{~km} / \mathrm{h}$ is used here to quantify the vibration velocity level. Very similar results are obtained if the average measured vibration velocity level due to different passages of the same train type in a limited speed range $(193-200 \mathrm{~km} / \mathrm{h})$ is used. Figure 12 shows the force density levels, determined with sources located at the edge of the sleeper and adjacent to the track. In the frequency range of $25-63 \mathrm{~Hz}$, the force density is relatively invariant with receiver distance, except for the $6 \mathrm{~m}$ response in figure 12(b), which may not be a useful metric due to the very small distance $(0.95 \mathrm{~m})$ between the excitation point and the receiver. Outside of this frequency range, a strong dependence of the force density on the receiver distance is observed, with differences of more than $10 \mathrm{~dB}$, ranging up to $15 \mathrm{~dB}$ in certain frequency bands, between the force density levels determined using receivers at $6 \mathrm{~m}$ and $64 \mathrm{~m}$. A maximum difference of $40 \mathrm{~dB}$ is observed in figure 12(b) at frequencies above $63 \mathrm{~Hz}$. The force density level in this region is dominated by the strong attenuation of the line source transfer mobility with increasing distance from the track. This suggests that the force density level cannot be considered to be uncoupled from the through-soil transfer functions. As the force density levels shown here have been determined from field measurements, they inherently account for the movement of the train and all the relevant details of the coupled train-track-soil system.
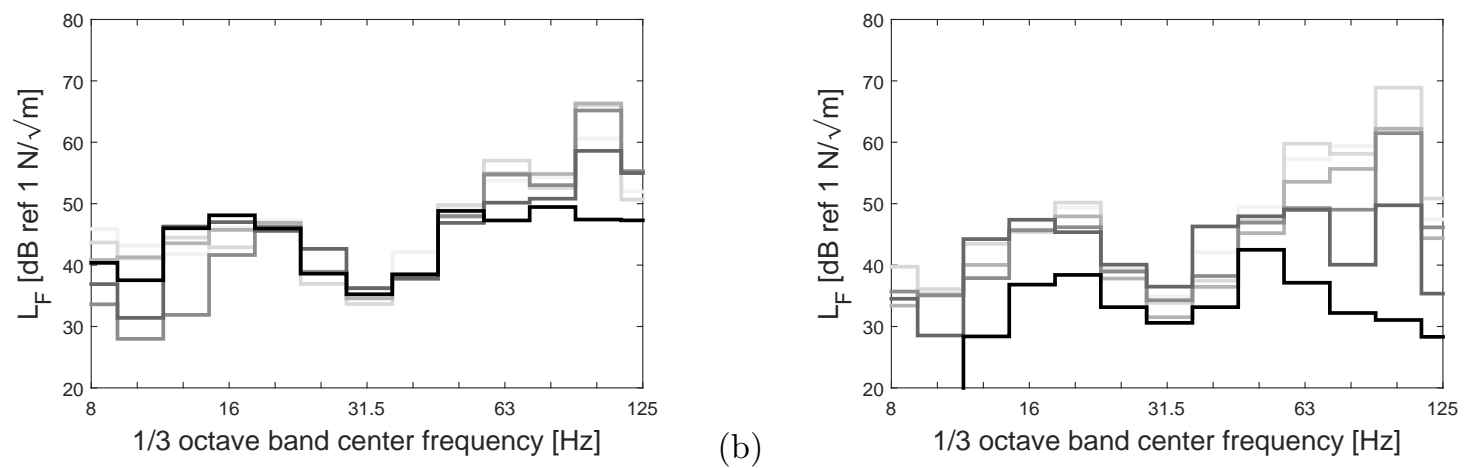

Figure 12: Measured force density level for sources located at (a) the edge of the sleeper and (b) the soil's surface adjacent to the track, calculated based on the response at $6 \mathrm{~m}, 12 \mathrm{~m}, 24 \mathrm{~m}, 32 \mathrm{~m}, 48 \mathrm{~m}$, and $64 \mathrm{~m}$ during the passage of an IC train (198 $\mathrm{km} / \mathrm{h}$ ). The distance from the track is indicated by the line shade, where a darker shade indicates a smaller distance. 


\section{Making predictions: hybrid methods}

\subsection{General framework}

Hybrid or semi-empirical models combine numerical and empirical methods, offering greater flexibility and robustness than a single modelling method. By integrating field measurements with state-of-the-art modelling techniques, the need for simplifying modelling assumptions and detailed parameter identification can be partially avoided. This is expected to result in a reduction of prediction uncertainty at a reduced cost. Hybrid models can also be employed in situations where there is not sufficient experimental data to fully characterise the source strength and the vibration transmission, such as when the vibration behaviour of new tracks, new trains, or the installation of vibration mitigation measures is to be evaluated. Hybrid models incorporating field measurements and numerical results into a single prediction are unexplored in the literature.

The ISO framework involving division of the vibration response into separate source and propagation terms forms an ideal basis for hybrid models, as each of the terms can be determined using field measurements, or calculated using numerical procedures. Thus two generic hybrid models are defined: model 1, which involves numerical prediction of the source term and a propagation term determined using field measurements:

$$
A^{\mathrm{HYB}}(f)=S^{\mathrm{NUM}}(f)+P^{\mathrm{EXP}}(f)
$$

and model 2, which involves determination of the source term using field measurements and numerical prediction of the propagation term:

$$
A^{\mathrm{HYB}}(f)=S^{\mathrm{EXP}}(f)+P^{\mathrm{NUM}}(f)
$$

where the superscripts HYB, NUM and EXP represent hybrid, numerical, and experimental (measured) means of calculating the vibration terms.

The use of a numerical prediction of the source term in model 1 is particularly suited to situations where a railway does not yet exist at the site of interest, or has only been partially constructed. This model also provides a means of easily assessing the effect of alterations to the track, such as the installation of track-based mitigation measures like resilient fasteners, rail pads and floating slab track, and alterations to the train, such as reduced wheel/rail roughness and increased train speed. The use of a measured propagation term offers resilience in the case of a site with complex soil stratification, avoiding both the expense of extensive soil characterisation tests and the modelling effort required to implement multiple soil layers. However, in situ measurements are still required to obtain transfer functions that characterise the propagation path.

Model 2 employs a measured source term that is particularly useful in situations where the track conditions/geometry are not well-suited to numerical modelling procedures. For example, it may not be possible to conduct in situ measurements of the track unevenness to determine the dynamic axle loads, or transition zones with changing track support stiffness may be present, which currently cannot be incorporated into 2.5D formulations. The use of a numerical prediction of the propagation term provides a means of assessing the effect of installing mitigation measures such as trenches, wave barriers and wave impeding blocks. This type of hybrid model can also significantly reduce the numerical model complexity by avoiding the need for characterisation of the track parameters and inclusion of the train and track elements.

\subsection{Model implementation: definition of terms}

The generic hybrid models can be implemented using any prescribed method of determining the source and propagation terms. In the following implementation, these terms are defined as per the FRA procedure described in Section 4. The determination of the line source transfer mobilities and force density terms using in situ measurements has already been described; here a summary of the derivation of analytical expressions for these terms is presented. The full derivation is found in Verbraken et al. [27].

Starting with equation (3), the assumptions of fixed, incoherent and equal point loads at the axles are systematically introduced. The narrow band transfer function is replaced by its averaged value in one-third 
octave bands and the mean square value of the stationary part of the vibration velocity $v_{\mathrm{RMS}}^{2}$ is determined in one-third octave bands. The vibration velocity level $\mathrm{L}_{\mathrm{v}}\left(\mathrm{x}^{\prime}\right)$ in the FRA procedure is defined as 10 times the logarithm to base 10 of $v_{\mathrm{RMS}}^{2}$ with respect to a reference value of $10^{-8} \mathrm{~m} / \mathrm{s}$. Separation of the source and propagation terms results in an analytical expression for the force density:

$$
\mathrm{L}_{\mathrm{F}}\left(\mathbf{x}^{\prime}\right)=10 \log _{10}\left[\frac{n_{\mathrm{a}}}{L_{\mathrm{t}}} g_{\mathrm{dRMS}}^{2}\right]
$$

and an analytical expression for the line source transfer mobility:

$$
\operatorname{TM}_{\mathrm{L}}\left(\mathbf{X}, \mathbf{x}^{\prime}\right)=10 \log _{10}\left[\frac{L_{\mathrm{t}}}{n_{\mathrm{a}}} \sum_{k=1}^{n_{\mathrm{a}}} \frac{\int_{\omega_{1}}^{\omega_{2}}\left|\hat{h}_{z z}\left(\mathbf{x}_{k}, \mathbf{x}^{\prime}, \omega\right)\right|^{2} d \omega}{\Delta \omega}\right]
$$

Equation (11) represents the force per unit length applied by the axles at the wheel/rail contact at a fixed position. It is calculated based on the spectrum of the dynamic axle loads of the train $g_{\mathrm{dRMS}}$, using equation (2) and expressed in one-third octave bands, and the ratio of the number of axles $n_{\mathrm{a}}$ to the train length $L_{\mathrm{t}}$. It should be noted that the term $g_{\mathrm{dRMS}}$ contains only the dynamic component of the axle loads. The static component of the axle loads manifests in the free field response as a quasi-static contribution that cannot be written in the form of equation (5). This quasi-static contribution is only significant at low frequencies when close to the track and can thus be neglected. The expression for the force density level is independent of the separation distance of the source and receiver, as a result of the approximations introduced at the start of this derivation. This expression will be referred to as the 'direct' method of calculating the force density level, cf. the 'indirect' method given in equation (8). It is only indirectly influenced by the speed of the train via the dynamic axle load term.

Equation (12) represents the average value of the vibration energy transfer for all axles multiplied by the train length. The term $\hat{h}_{z z}\left(\mathbf{x}_{k}, \mathbf{x}^{\prime}, \omega\right)$ is the transfer function relating the displacement at receiver point $\mathbf{x}^{\prime}$ in the direction $\mathbf{e}_{z}$ due to a point load at source point $\mathbf{x}_{k}$ in direction $\mathbf{e}_{z}$, and is first averaged over the frequency band $\left[\omega_{1}, \omega_{2}\right]$ with bandwidth $\Delta \omega$, then summed over the total number of axles. This expression for the line source transfer mobility is dependent, yet relatively insensitive, to the exact position of the axles and the number of source points considered [10].

The line source transfer mobility can also be written as the superposition of point source transfer mobilities:

$$
\mathrm{TM}_{\mathrm{L}}=10 \log _{10}\left[L_{\mathrm{a}} \sum_{k=1}^{n_{\mathrm{a}}} 10 \frac{\mathrm{TM}_{\mathrm{P}_{k}}}{10}\right]
$$

where $\mathrm{TM}_{\mathrm{P}_{k}}$ is defined as:

$$
\mathrm{TM}_{\mathrm{P}_{k}}=10 \log _{10}\left[\frac{\int_{\omega_{1}}^{\omega_{2}}\left|\hat{h}_{z z}\left(\mathbf{x}_{k}, \mathbf{x}^{\prime}, \omega\right)\right|^{2} d \omega}{\Delta \omega}\right]
$$

Each of these point loads are located at the position of the corresponding axle; however, the FRA procedure uses point loads that are distributed equidistantly along the train. Coupled FE-BE analysis shows that the use of equidistant loads, together with the other assumptions used in this derivation, are valid for the case of predicting the approximately stationary part of the vibrations due to railway traffic [27]. It is estimated that these assumptions introduce errors of the order of 4 to $6 \mathrm{~dB}$ in the one-third octave band predictions [10].

Figure 13 shows the directly predicted force density level for the passage of an IC-A train $(198 \mathrm{~km} / \mathrm{h})$, calculated using the dynamic axle loads and equation (11). The maximum force density level is occurring in the one-third octave bands centered on $50 \mathrm{~Hz}, 63 \mathrm{~Hz}$ and $80 \mathrm{~Hz}$.

To calculate the line source transfer mobility, excitation forces are applied to the track submodel with a spacing of $10 \mathrm{~m}$ over a distance of $160 \mathrm{~m}$. To maintain consistency with the in situ measurements, the impact locations are at the edge of the sleeper and on the soil's surface adjacent to the track. Figure 14 shows the calculated line source transfer mobility levels. These calculated level are similar to the measured line source transfer mobilities shown in figure 11, except at high frequencies. 


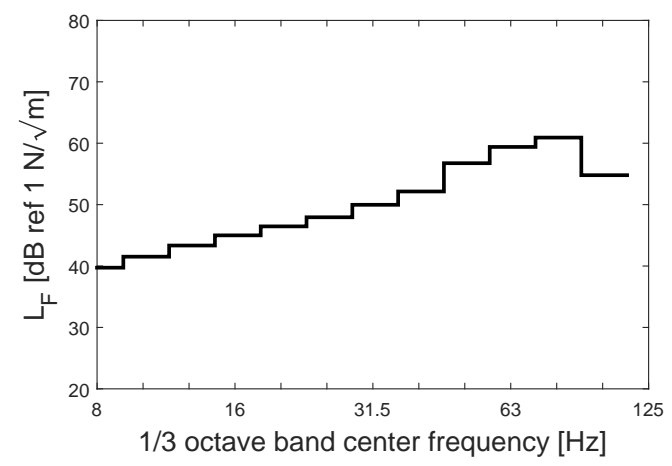

Figure 13: Directly predicted force density level for an IC-A train $(198 \mathrm{~km} / \mathrm{h})$.

(a)

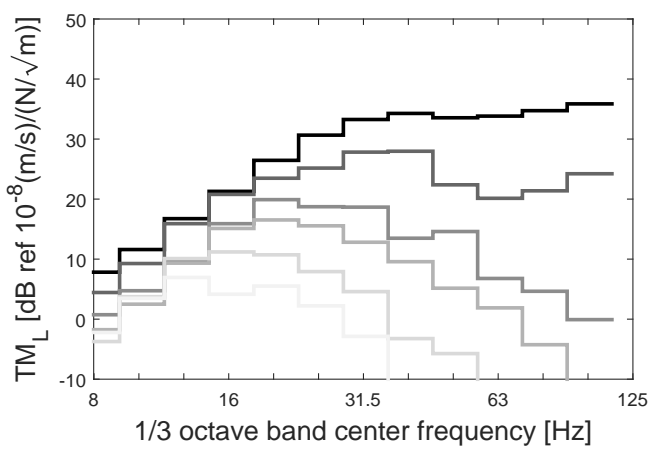

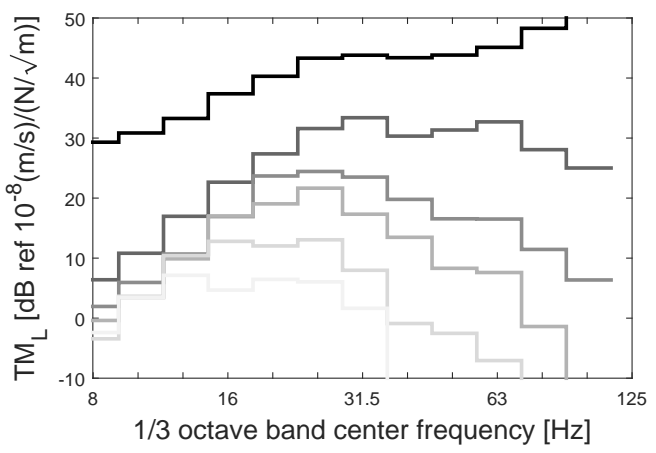

Figure 14: Predicted line source transfer mobility level for sources located at (a) the edge of the sleeper and (b) adjacent to the track, with receivers at $6 \mathrm{~m}, 12 \mathrm{~m}, 24 \mathrm{~m}, 32 \mathrm{~m}, 48 \mathrm{~m}$, and $64 \mathrm{~m}$. The distance from the track is indicated by the line shade, where a darker shade indicates a smaller distance.

The numerical force density level can also be calculated indirectly using the difference between the vibration velocity level and the line source transfer mobility. Figure 15 shows the indirectly predicted force density level based on the response at $6 \mathrm{~m}, 12 \mathrm{~m}, 24 \mathrm{~m}, 32 \mathrm{~m}, 48 \mathrm{~m}$, and $64 \mathrm{~m}$ and determined with sources located at the edge of the sleeper and adjacent to the track. As observed for the measured force density levels in figure 12, the force density levels are relatively invariant with distance in the frequency range of $25-50 \mathrm{~Hz}$, if the $6 \mathrm{~m}$ response in figure 15(b) is ignored. Again, a greater degree of dependance on receiver position is observed outside of this frequency range, particularly above $50 \mathrm{~Hz}$ in figure $15(\mathrm{~b})$. Unlike for the direct prediction method, these force density levels do account for the movement of the train and are dependent upon the receiver position.

\subsection{Model implementation: model 1}

The first hybrid model presented in this paper combines a numerical prediction of the force density with a line source transfer mobility determined using field measurements. There are two possible methods for obtaining the numerical prediction of the force density.

\subsubsection{Model 1a: direct numerical prediction of the force density}

Direct prediction uses an analytical expression for the force density, derived in subsection 5.2, which uses source points $\mathbf{X}$ located at both rail heads and is independent of the receiver location. The resulting hybrid model is described using the equation:

$$
\mathrm{L}_{\mathrm{v}}^{\mathrm{HYB}}\left(\mathbf{x}^{\prime}\right)=\mathrm{L}_{\mathrm{F}}^{\mathrm{NUM}}(\mathbf{X})+\mathrm{TM}_{\mathrm{L}}^{\mathrm{EXP}}\left(\mathbf{X}, \mathbf{x}^{\prime}\right)
$$

As this model does not fully account for the movement of the train, it is expected that more accurate predictions will be obtained using an indirect numerical prediction of the force density, given below. 

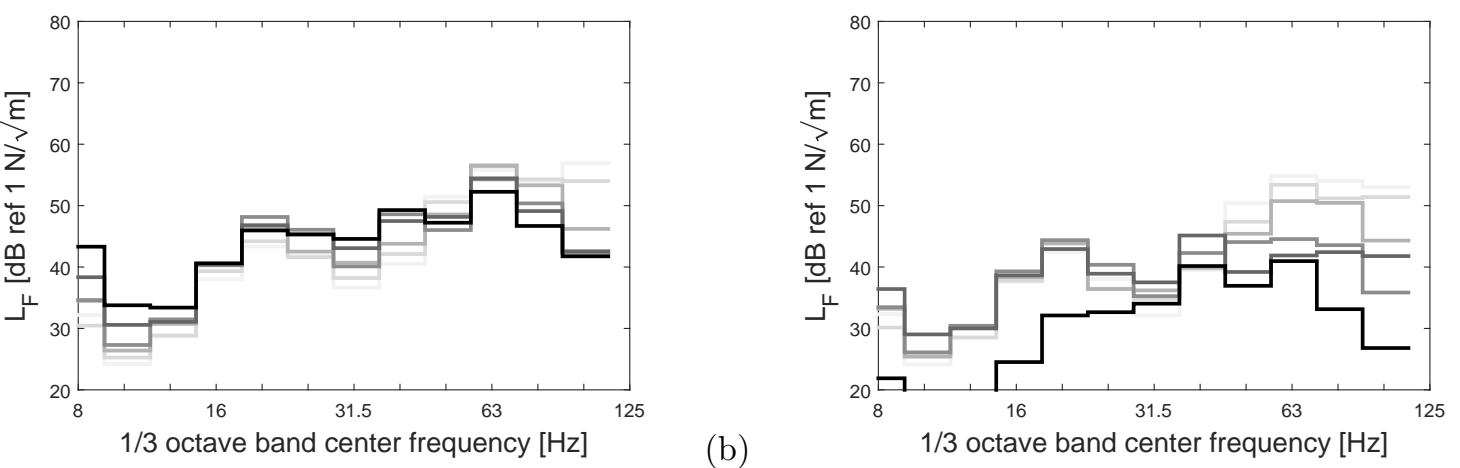

(a)

Figure 15: Indirectly predicted force density level for sources located at (a) the edge of the sleeper and (b) adjacent to the track, based on the response at $6 \mathrm{~m}, 12 \mathrm{~m}, 24 \mathrm{~m}, 32 \mathrm{~m}, 48 \mathrm{~m}$, and $64 \mathrm{~m}$ during the passage of an IC train $(198 \mathrm{~km} / \mathrm{h})$. The distance from the track is indicated by the line shade, where a darker shade indicates a smaller distance.

\subsubsection{Model 1b: indirect numerical prediction of the force density}

The second method for obtaining the numerical prediction of the force density is the indirect prediction method that utilises the difference between the numerical prediction of the vibration velocity level and the numerical line source transfer line mobility:

$$
\mathrm{L}_{\mathrm{F}}^{\mathrm{NUM}}\left(\mathbf{X}, \mathbf{x}^{\prime}\right)=\mathrm{L}_{\mathrm{v}}^{\mathrm{NUM}}\left(\mathbf{x}^{\prime}\right)-\mathrm{TM}_{\mathrm{L}}^{\mathrm{NUM}}\left(\mathbf{X}, \mathbf{x}^{\prime}\right)
$$

This results in a force density level $\mathrm{L}_{\mathrm{F}}^{\mathrm{NUM}}\left(\mathbf{X}, \mathbf{x}^{\prime}\right)$ that depends on both the source $\mathbf{X}$ and receiver $\mathbf{x}^{\prime}$ locations. The hybrid model expression is therefore:

$$
\mathrm{L}_{\mathrm{v}}^{\mathrm{HYB}}\left(\mathbf{x}^{\prime}\right)=\mathrm{L}_{\mathrm{F}}^{\mathrm{NUM}}\left(\mathbf{X}, \mathbf{x}^{\prime}\right)+\mathrm{TM}_{\mathrm{L}}^{\mathrm{EXP}}\left(\mathbf{X}, \mathbf{x}^{\prime}\right)
$$

and substitution of equation (16) yields:

$$
\mathrm{L}_{\mathrm{v}}^{\mathrm{HYB}}\left(\mathbf{x}^{\prime}\right)=\mathrm{L}_{\mathrm{v}}^{\mathrm{NUM}}\left(\mathbf{x}^{\prime}\right)-\mathrm{TM}_{\mathrm{L}}^{\mathrm{NUM}}\left(\mathbf{X}, \mathbf{x}^{\prime}\right)+\mathrm{TM}_{\mathrm{L}}^{\mathrm{EXP}}\left(\mathbf{X}, \mathbf{x}^{\prime}\right)
$$

This expression represents a numerical prediction of the vibration velocity at the receiver location $\mathbf{x}^{\prime}$, with a correction term $\mathrm{TM}_{\mathrm{L}}^{\mathrm{EXP}}\left(\mathbf{X}, \mathbf{x}^{\prime}\right)-\mathrm{TM}_{\mathrm{L}}^{\mathrm{NUM}}\left(\mathbf{X}, \mathbf{x}^{\prime}\right)$ to account for the vibration propagation measurements. This correction term is expected to reduce the prediction error in the numerical model due to simplifying assumptions and parameter uncertainty in the underground environment, which is particularly pertinent when complex soil stratification is present.

\subsubsection{Alternative source locations}

The numerical predictions for the force density level have, up to now, been determined with source points $\mathbf{X}$ located at the rail heads, and have been combined in hybrid models with measured line source transfer mobility levels that are also determined with source points $\mathbf{X}$ at the rail heads. In the event that alternative source locations are required (such as the illustration in figure 10(a), where a track is not present at the site of interest), source point locations $\mathbf{X}_{1}$ away from the railhead can be used for both the force density level and the line source transfer mobility:

$$
\mathrm{L}_{\mathrm{v}}^{\mathrm{HYB}}\left(\mathbf{x}^{\prime}\right)=\mathrm{L}_{\mathrm{F}}^{\mathrm{NUM}}\left(\mathbf{X}_{1}, \mathbf{x}^{\prime}\right)+\mathrm{TM}_{\mathrm{L}}^{\mathrm{EXP}}\left(\mathbf{X}_{1}, \mathbf{x}^{\prime}\right)
$$

This expression uses an indirect prediction of the numerical force density $\mathrm{L}_{\mathrm{F}}^{\mathrm{NUM}}\left(\mathbf{X}_{1}, \mathbf{x}^{\prime}\right)$ with source points at $\mathbf{X}_{1}$, which is given by:

$$
\mathrm{L}_{\mathrm{F}}^{\mathrm{NUM}}\left(\mathbf{X}_{1}, \mathbf{x}^{\prime}\right)=\mathrm{L}_{\mathrm{v}}^{\mathrm{NUM}}\left(\mathbf{x}^{\prime}\right)-\mathrm{TM}_{\mathrm{L}}^{\mathrm{NUM}}\left(\mathbf{X}_{1}, \mathbf{x}^{\prime}\right)
$$

Substituting this into equation (19) results in:

$$
\mathrm{L}_{\mathrm{v}}^{\mathrm{HYB}}\left(\mathbf{x}^{\prime}\right)=\mathrm{L}_{\mathrm{v}}^{\mathrm{NUM}}\left(\mathbf{x}^{\prime}\right)-\mathrm{TM}_{\mathrm{L}}^{\mathrm{NUM}}\left(\mathbf{X}_{1}, \mathbf{x}^{\prime}\right)+\mathrm{TM}_{\mathrm{L}}^{\mathrm{EXP}}\left(\mathbf{X}_{1}, \mathbf{x}^{\prime}\right)
$$


This expression is the alternative to equation (18), and is suitable for indirect numerical prediction of the force density with sources located away from the rail heads, for example on the sleeper's edge or next to the track. It can be regarded as a numerical prediction of the vibration velocity level at receiver location $\mathbf{x}^{\prime}$ together with a transfer function correction term $\operatorname{TM}_{\mathrm{L}}^{\mathrm{EXP}}\left(\mathbf{X}_{1}, \mathbf{x}^{\prime}\right)-\mathrm{TM}_{\mathrm{L}}^{\mathrm{NUM}}\left(\mathbf{X}_{1}, \mathbf{x}^{\prime}\right)$ that makes use of the alternative source location $\mathbf{X}_{1}$ to account for the propagation path measurements.

The numerical vibration velocity $\mathrm{L}_{\mathrm{v}}^{\mathrm{NUM}}\left(\mathbf{x}^{\prime}\right)$ can be obtained using the direct expression for the force density:

$$
\mathrm{L}_{\mathrm{v}}^{\mathrm{NUM}}\left(\mathbf{x}^{\prime}\right)=\mathrm{L}_{\mathrm{F}}^{\mathrm{NUM}}(\mathbf{X})+\mathrm{TM}_{\mathrm{L}}^{\mathrm{NUM}}\left(\mathbf{X}, \mathbf{x}^{\prime}\right)
$$

resulting in:

$$
\mathrm{L}_{\mathrm{v}}^{\mathrm{HYB}}\left(\mathbf{x}^{\prime}\right)=\mathrm{L}_{\mathrm{F}}^{\mathrm{NUM}}(\mathbf{X})+\mathrm{TM}_{\mathrm{L}}^{\mathrm{NUM}}\left(\mathbf{X}, \mathbf{x}^{\prime}\right)-\mathrm{TM}_{\mathrm{L}}^{\mathrm{NUM}}\left(\mathbf{X}_{1}, \mathbf{x}^{\prime}\right)+\mathrm{TM}_{\mathrm{L}}^{\mathrm{EXP}}\left(\mathbf{X}_{1}, \mathbf{x}^{\prime}\right)
$$

This expression is the alternative to equation (15), and is suitable for direct numerical prediction of the force density with sources located away from the rail heads. It combines the analytical expression for the force density with a measured line source transfer mobility using source location $\mathbf{X}_{1}$. The difference in source point locations is accounted for in the numerical correction term $\operatorname{TM}_{\mathrm{L}}^{\mathrm{NUM}}\left(\mathbf{X}, \mathbf{x}^{\prime}\right)-\mathrm{TM}_{\mathrm{L}}^{\mathrm{NUM}}\left(\mathbf{X}_{1}, \mathbf{x}^{\prime}\right)$.

\subsection{Model implementation: model 2}

The second hybrid model combines field measurements of the force density with a numerical prediction of the line source transfer mobility. The resulting hybrid model is described using the equation:

$$
\mathrm{L}_{\mathrm{v}}^{\mathrm{HYB}}\left(\mathbf{x}^{\prime}\right)=\mathrm{L}_{\mathrm{F}}^{\mathrm{EXP}}\left(\mathbf{X}, \mathbf{x}^{\prime}\right)+\mathrm{TM}_{\mathrm{L}}^{\mathrm{NUM}}\left(\mathbf{X}, \mathbf{x}^{\prime}\right)
$$

which involves source locations $\mathbf{X}$ at the rail heads for determining both the force density and the line source transfer mobility.

As per the FRA procedure, the measured force density is determined as the difference between the measured vibration velocity level and the line source transfer mobility:

$$
\mathrm{L}_{\mathrm{F}}^{\mathrm{EXP}}\left(\mathbf{X}, \mathbf{x}^{\prime}\right)=\mathrm{L}_{\mathrm{v}}^{\mathrm{EXP}}\left(\mathbf{x}^{\prime}\right)-\mathrm{TM}_{\mathrm{L}}^{\mathrm{EXP}}\left(\mathbf{X}, \mathbf{x}^{\prime}\right)
$$

The hybrid model expression is therefore:

$$
\mathrm{L}_{\mathrm{v}}^{\mathrm{HYB}}\left(\mathbf{x}^{\prime}\right)=\mathrm{L}_{\mathrm{v}}^{\mathrm{EXP}}\left(\mathbf{x}^{\prime}\right)-\mathrm{TM}_{\mathrm{L}}^{\mathrm{EXP}}\left(\mathbf{X}, \mathbf{x}^{\prime}\right)+\mathrm{TM}_{\mathrm{L}}^{\mathrm{NUM}}\left(\mathbf{X}, \mathbf{x}^{\prime}\right)
$$

This expression represents a measured vibration velocity at the receiver location $\mathbf{x}^{\prime}$, with a numerical adjustment of the propagation path term $\operatorname{TM}_{\mathrm{L}}^{\mathrm{NUM}}\left(\mathbf{X}, \mathbf{x}^{\prime}\right)-\mathrm{TM}_{\mathrm{L}}^{\mathrm{EXP}}\left(\mathbf{X}, \mathbf{x}^{\prime}\right)$. This model would be relevant when the effect of a modification to the vibration propagation path of an existing railway is to be evaluated. Examples of such modifications include open trenches [28], soft or stiff wave barriers [29, 30], and heavy masses next to the track [31], all of which have been shown to impede the transmission of waves through the soil.

\subsubsection{Alternative source locations}

As per model 1, a hybrid model expression can be formulated for situations where the source point locations $\mathbf{X}_{1}$ are located away from the rail heads:

$$
\mathrm{L}_{\mathrm{v}}^{\mathrm{HYB}}\left(\mathbf{x}^{\prime}\right)=\mathrm{L}_{\mathrm{F}}^{\mathrm{EXP}}\left(\mathbf{X}_{1}, \mathbf{x}^{\prime}\right)+\mathrm{TM}_{\mathrm{L}}^{\mathrm{NUM}}\left(\mathbf{X}_{1}, \mathbf{x}^{\prime}\right)
$$

If the source point locations are on the soil surface, sufficiently far from the track, the presence of the track could be disregarded in the calculation of the line source transfer mobility. This will result in significant computational savings, as the need for characterisation of the excitation mechanism and the track can be avoided when formulating the numerical model.

Using the FRA procedure to determine the measured force density (equation (25)) results in:

$$
\mathrm{L}_{\mathrm{v}}^{\mathrm{HYB}}\left(\mathbf{x}^{\prime}\right)=\mathrm{L}_{\mathrm{v}}^{\mathrm{EXP}}\left(\mathbf{x}^{\prime}\right)-\mathrm{TM}_{\mathrm{L}}^{\mathrm{EXP}}\left(\mathbf{X}_{1}, \mathbf{x}^{\prime}\right)+\mathrm{TM}_{\mathrm{L}}^{\mathrm{NUM}}\left(\mathbf{X}_{1}, \mathbf{x}^{\prime}\right)
$$

This expression is the alternative to equation (26) and is suitable for numerical prediction of the line source transfer mobility with sources located away from the rail heads. It combines a measured vibration velocity level at receiver location $\mathbf{x}^{\prime}$ with a transfer function adjustment term $\operatorname{TM}_{\mathrm{L}}^{\mathrm{NUM}}\left(\mathbf{X}_{1}, \mathbf{x}^{\prime}\right)-\mathrm{TM}_{\mathrm{L}}^{\mathrm{EXP}}\left(\mathbf{X}_{1}, \mathbf{x}^{\prime}\right)$ that makes use of the alternative source location $\mathbf{X}_{1}$ to account for modification to the vibration propagation path. 


\section{Results}

In this section, the free field vibration levels predicted using the hybrid models are compared with vibrations predicted using the numerical model, and measured during the passage of an IC-A train travelling at $198 \mathrm{~km} / \mathrm{h}$.

\subsection{Model 1a: direct numerical prediction of the force density}

The first hybrid model results involve a direct numerical prediction of the force density that is combined with a measured line source transfer mobility. Sources located at the edge of the sleeper have been used for the measurements, hence a numerical correction factor is used to account for the offset between the rail heads and the edge of the sleeper, as per equation (23). Figure 16 shows the resulting hybrid prediction. The agreement between the hybrid model and the measurements is within $10 \mathrm{~dB}$. The numerical model predictions show very good agreement with the measured results, and in some instances this agreement is better than that obtained using the hybrid method. This good agreement is attributed to the fact that the site at Lincent has been specially selected for model validation purposes, due to its site topography being ideal for incorporation into numerical models. Furthermore, extensive testing efforts have provided detailed data on the site parameters for use in the numerical models.

\subsection{Model 1b: indirect numerical prediction of the force density}

Figures 17 and 18 show the results of the hybrid model described in equation (21), which combines an indirect numerical prediction of the force density with a measured line source transfer mobility using sources located at the edge of the sleeper and at the soil's surface adjacent to the track, respectively. The source points at the edge of the sleeper provide a hybrid prediction that is in marginally better agreement with the measured results than that obtained using source points adjacent to the track.

The agreement between this hybrid model and the field measurements is generally within $6 \mathrm{~dB}$. This level of agreement is better than that obtained using model 1a, the direct numerical prediction of the force density. One reason for this is that the movement of the train is accounted for in the indirect prediction method, but disregarded in the direct prediction method.

\subsection{Model 2: numerical prediction of the line source transfer mobility}

The final hybrid model combines a measured force density level, using sources located at the edge of the sleeper and on the soil's surface, with a numerical prediction of the line source transfer mobility, as described in equation (28). These results are shown in figures 19 and 20. The hybrid model can be considered to represent a measured free field vibration level, with an adjustment of the transfer function $\mathrm{TM}_{\mathrm{L}}^{\mathrm{NUM}}\left(\mathbf{X}_{1}, \mathbf{x}^{\prime}\right)-\mathrm{TM}_{\mathrm{L}}^{\mathrm{EXP}}\left(\mathbf{X}_{1}, \mathbf{x}^{\prime}\right)$. This adjustment is relevant when the effect of a modification to the propagation path is to be evaluated. As this is not the case here, the difference between the hybrid model results and the measured free field level indicates the prediction accuracy of the numerical method for determining the line source transfer mobility level. Whilst this is useful for validating the numerical model, it has little practical significance. Both figures show relatively good agreement between the predictions and the measurements. Varying the source position has little effect.

\section{Conclusions}

This paper has presented two hybrid models for predicting surface vibration levels generated by a railway at grade. The first model combines a measured transfer mobility with a numerical prediction of the force density level, calculated either directly from an analytical expression or indirectly using the difference between predicted vibration velocity levels and a predicted line source transfer mobility. This model provides a means of easily assessing different track arrangements and offers resilience in the case of a site with complex soil stratification. The second model combines a measured force density with a numerical prediction of the transfer mobility and can be used to determine the effect of the installation of a mitigation measure within the propagation path. Both models show generally good agreement with measurements 


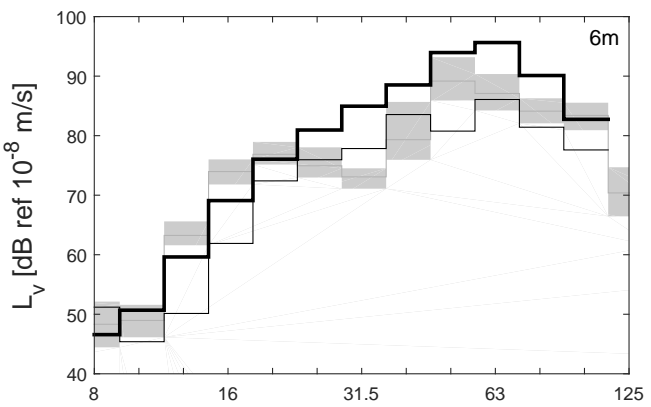

(a)

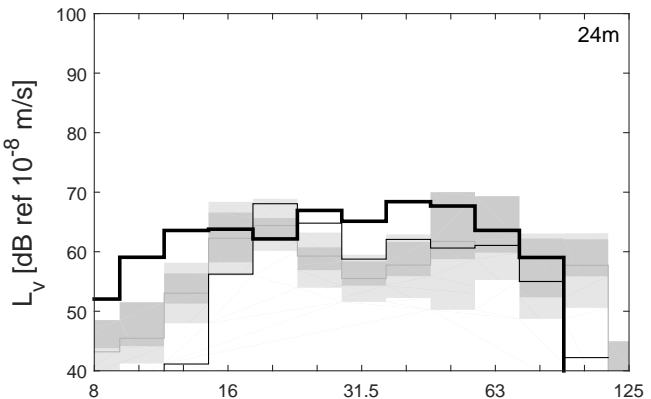

(c)

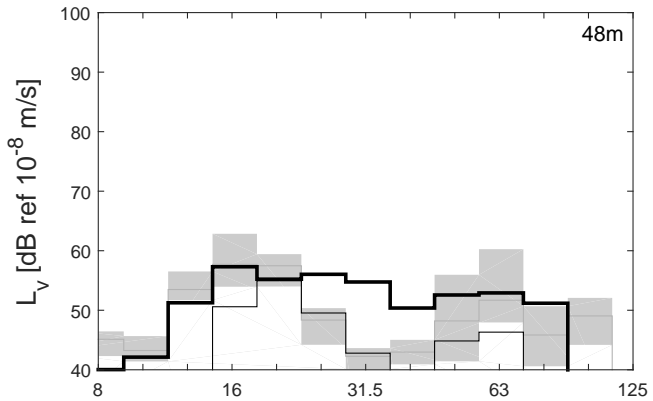

(e)

$1 / 3$ octave band center frequency [Hz]

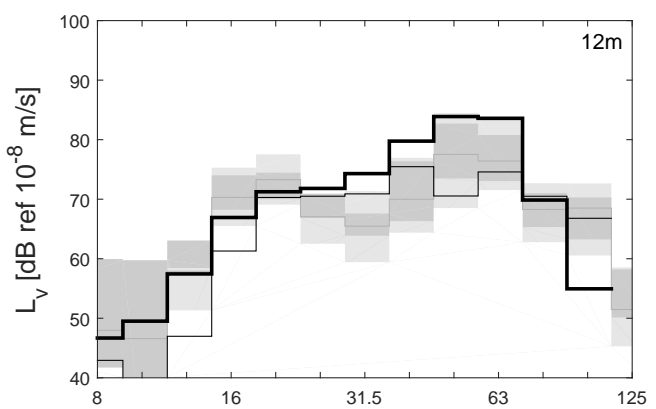

(b)

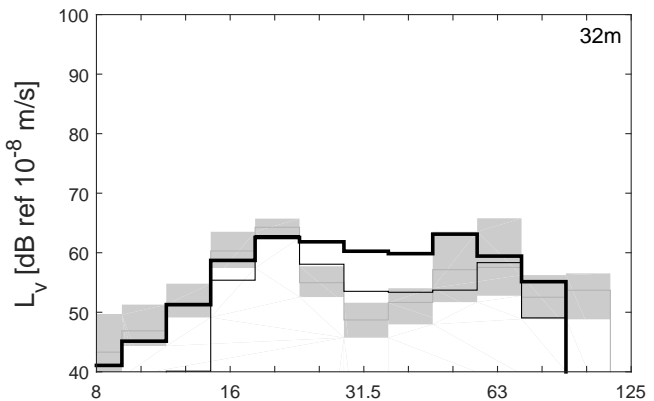

(d)

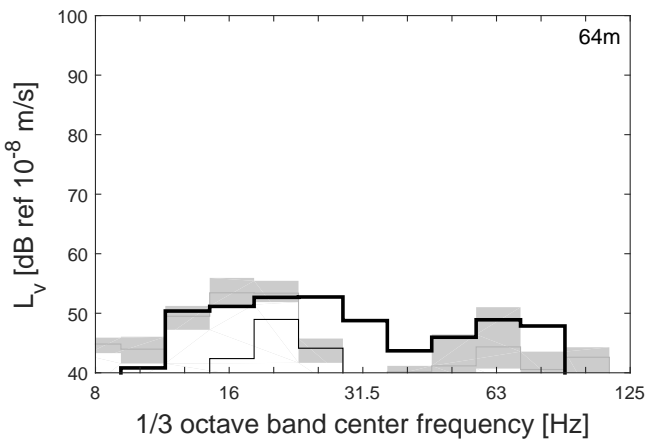

Figure 16: Hybrid prediction of the vibration velocity level at (a) $6 \mathrm{~m}$, (b) $12 \mathrm{~m}$, (c) $24 \mathrm{~m}$, (d) $32 \mathrm{~m}$, (e) $48 \mathrm{~m}$, and (f) $64 \mathrm{~m}$ for an IC train $(198 \mathrm{~km} / \mathrm{h}$ ), based on a directly predicted force density level (thick black line), numerical prediction (thin black line), and measured bounds for similar train speeds (dark shaded region) and adjacent receiver locations (light shaded region). The line source transfer mobility has been measured using sources located at the edge of the sleeper. 


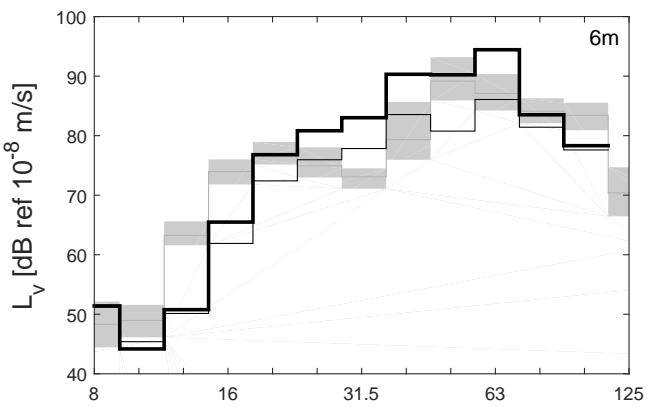

(a)

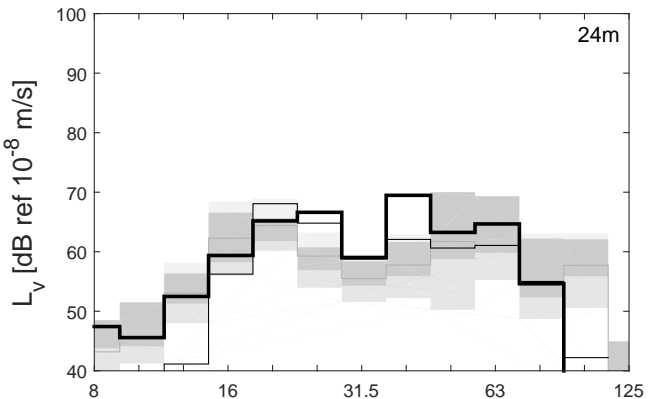

(c)

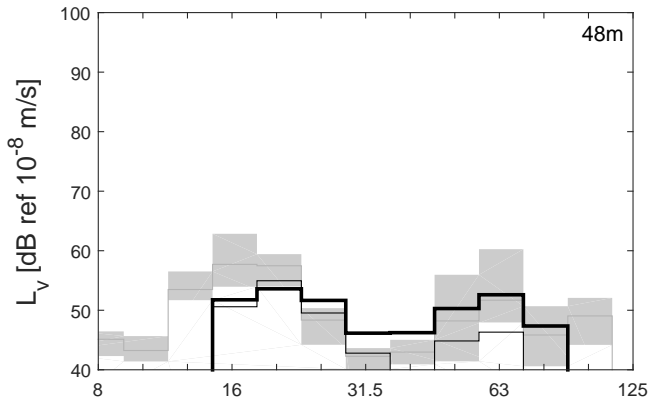

(e)

$1 / 3$ octave band center frequency [Hz]

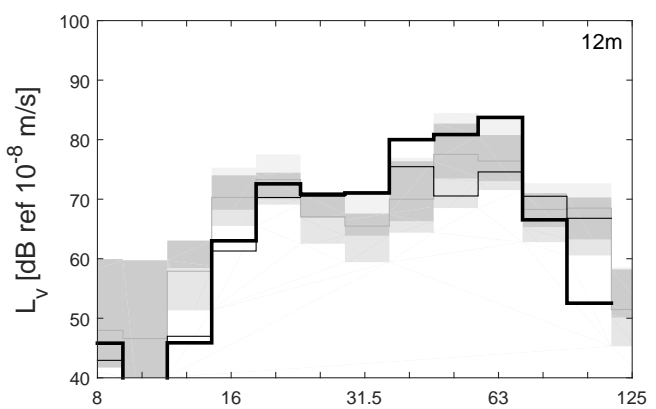

(b)

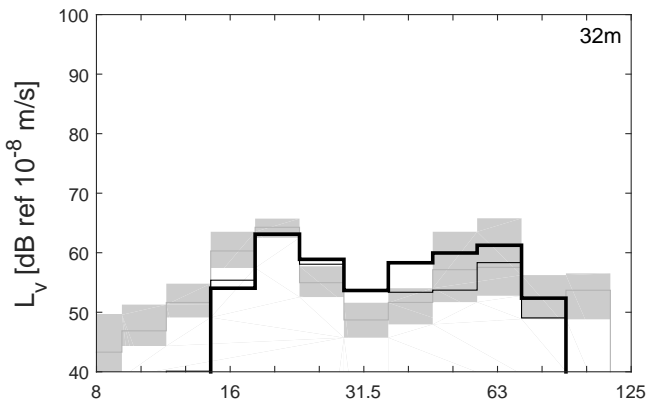

(d)

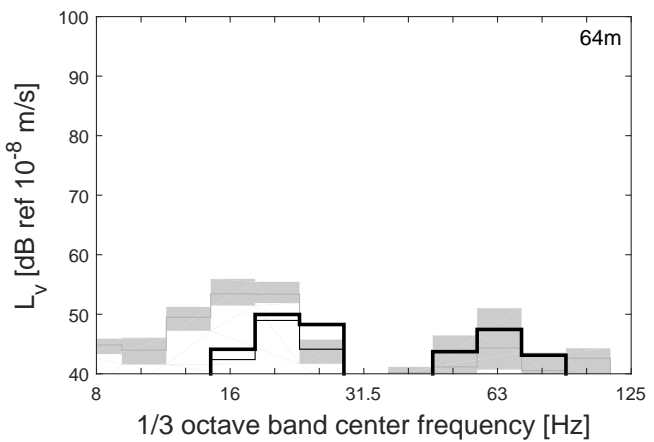

Figure 17: Hybrid prediction of the vibration velocity level at (a) $6 \mathrm{~m}$, (b) $12 \mathrm{~m}$, (c) $24 \mathrm{~m}$, (d) $32 \mathrm{~m}$, (e) $48 \mathrm{~m}$, and (f) $64 \mathrm{~m}$ for an IC train $(198 \mathrm{~km} / \mathrm{h})$, based on an indirectly predicted force density level determined with sources located at the edge of the sleeper (thick black line), numerical prediction (thin black line), and measured bounds for similar train speeds (dark shaded region) and adjacent receiver locations (light shaded region). 


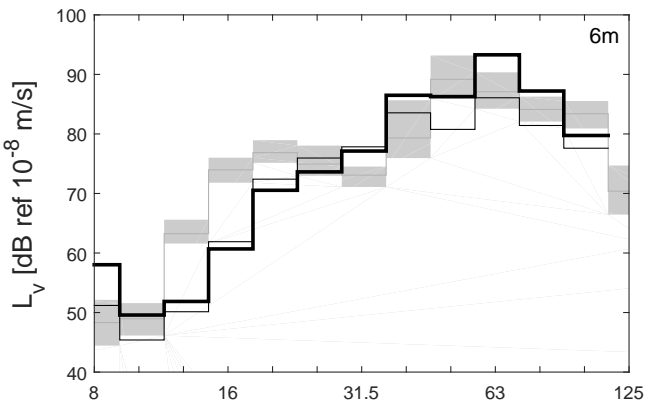

(a)

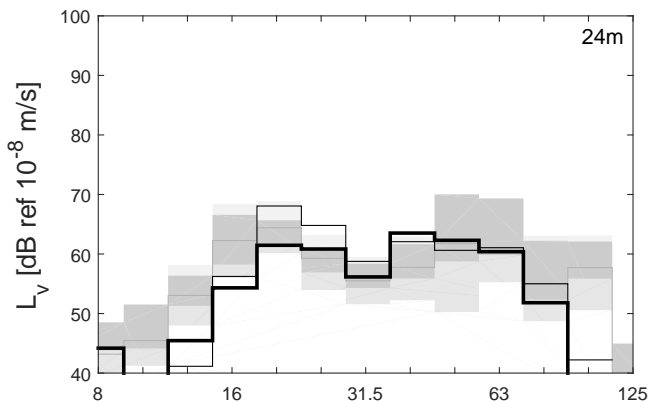

(c)

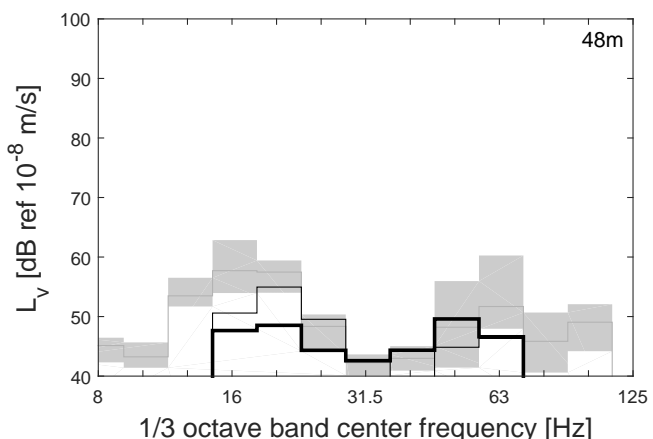

(b)
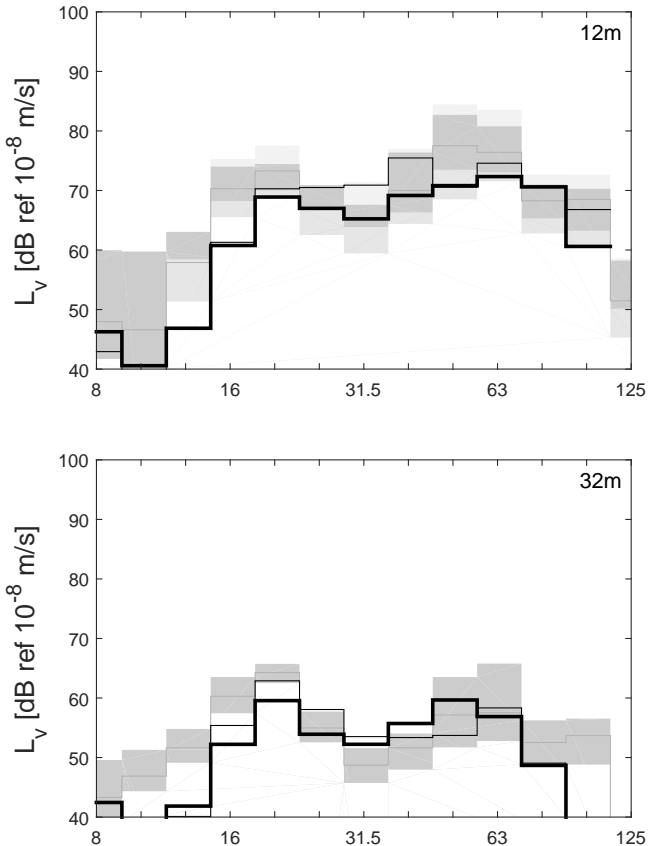

(d)

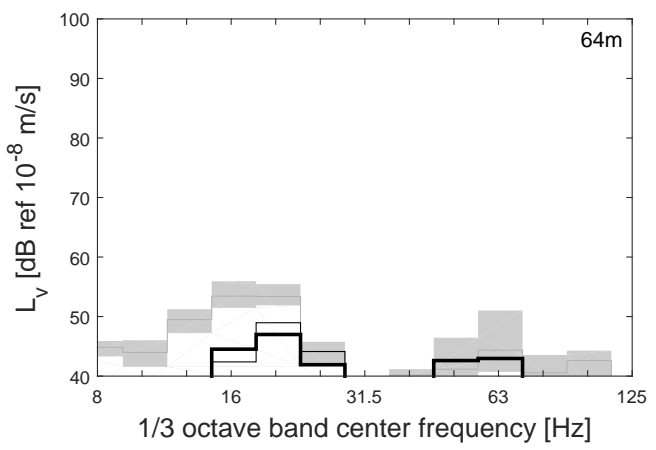

Figure 18: Hybrid prediction of the vibration velocity level at (a) $6 \mathrm{~m}$, (b) $12 \mathrm{~m}$, (c) $24 \mathrm{~m}$, (d) $32 \mathrm{~m}$, (e) $48 \mathrm{~m}$, and (f) $64 \mathrm{~m}$ for an IC train $(198 \mathrm{~km} / \mathrm{h})$, based on an indirectly predicted force density level determined with source points at the soil's surface adjacent to the track (thick black line), numerical prediction (thin black line), and measured bounds for similar train speeds (dark shaded region) and adjacent receiver locations (light shaded region). 


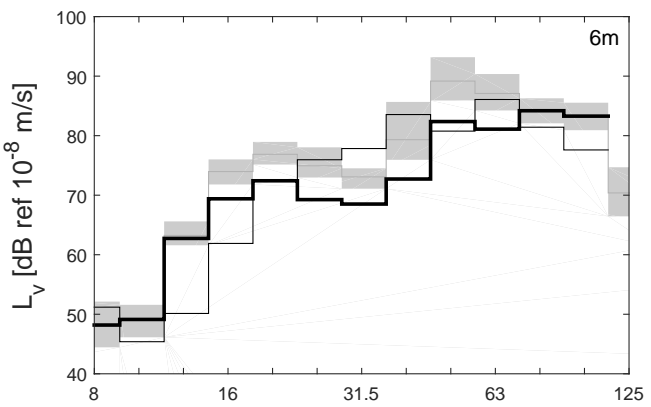

(a)

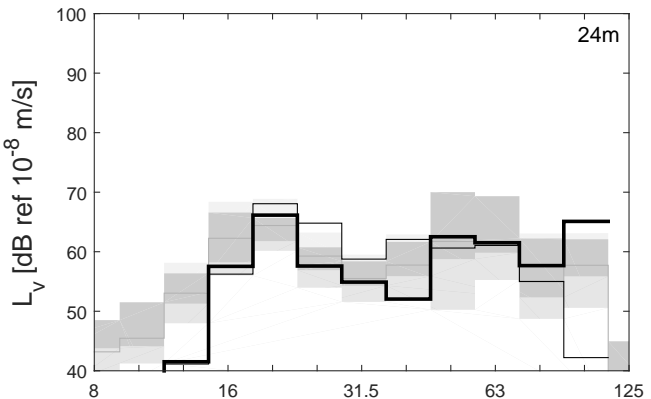

(c)

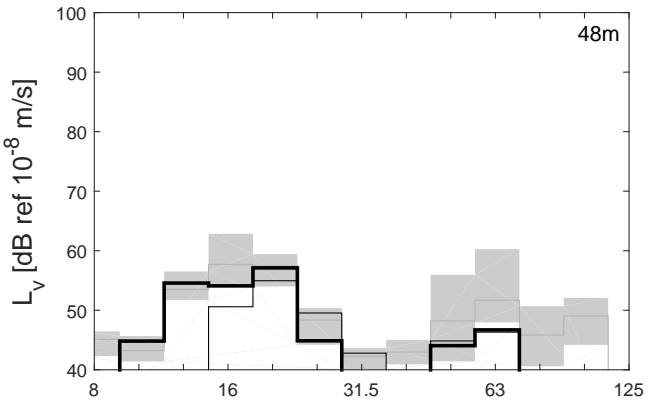

(e)

$1 / 3$ octave band center frequency $[\mathrm{Hz}]$

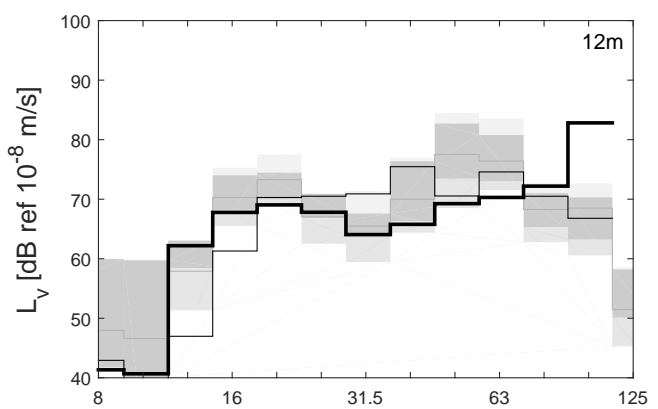

(b)

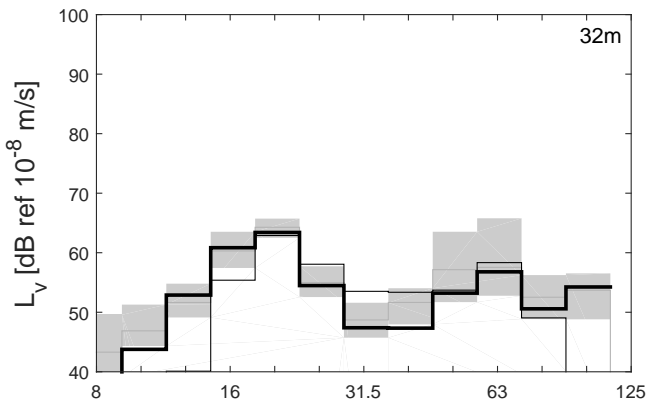

(d)

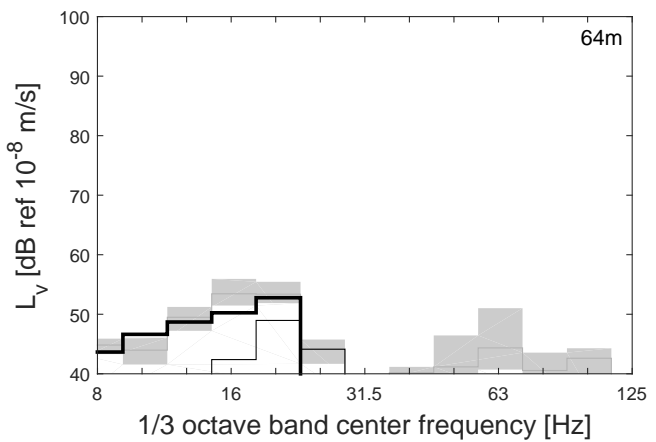

Figure 19: Hybrid prediction of the vibration velocity level at (a) $6 \mathrm{~m}$, (b) $12 \mathrm{~m}$, (c) $24 \mathrm{~m}$, (d) $32 \mathrm{~m}$, (e) $48 \mathrm{~m}$, and (f) $64 \mathrm{~m}$ for an IC train $(198 \mathrm{~km} / \mathrm{h})$, based on a predicted line source transfer mobility level determined with source points at the edge of the sleeper (thick black line), numerical prediction (thin black line), and measured bounds for similar train speeds (dark shaded region) and adjacent receiver locations (light shaded region). 


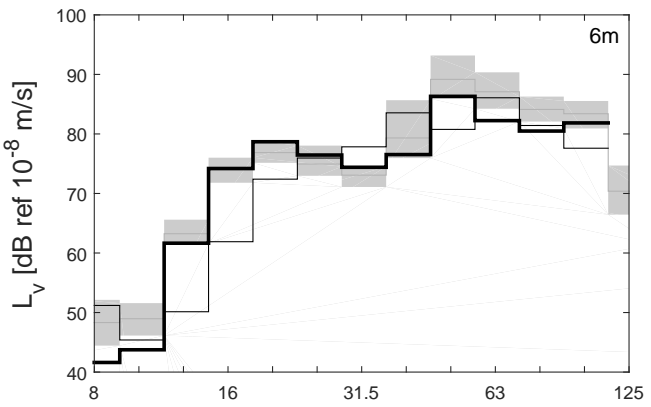

(a)

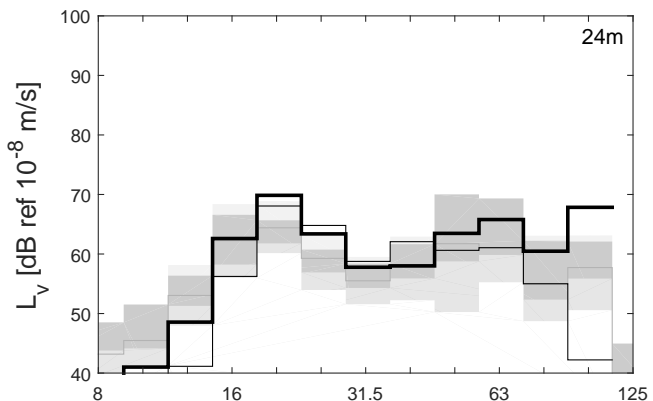

(c)

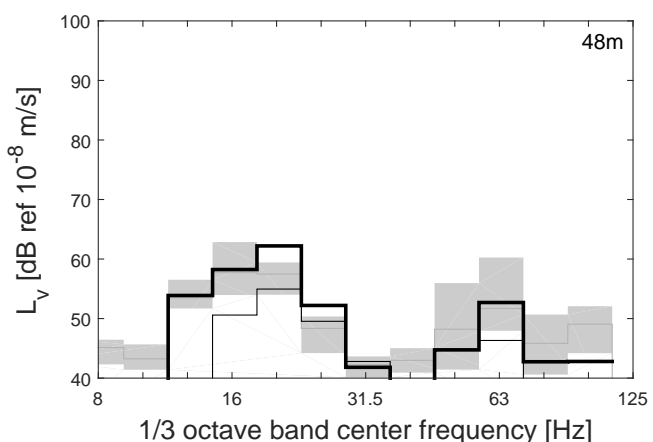

(b)
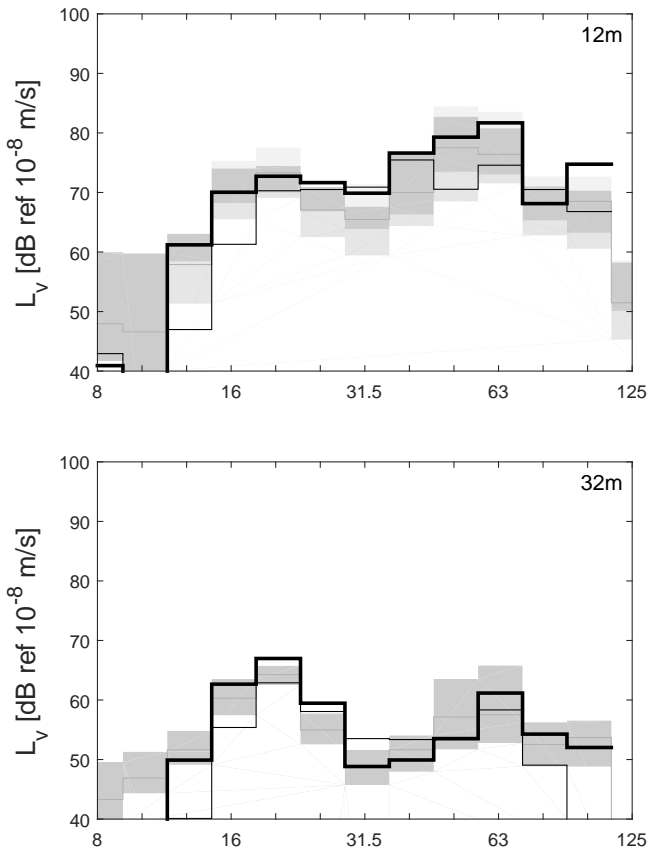

(d)

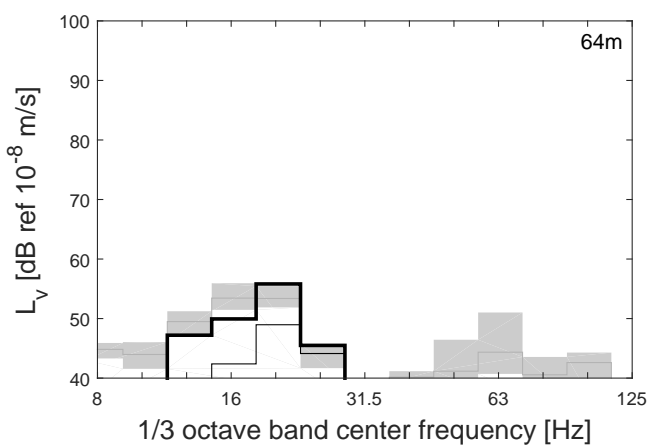

Figure 20: Hybrid prediction of the vibration velocity level at (a) $6 \mathrm{~m}$, (b) $12 \mathrm{~m}$, (c) $24 \mathrm{~m}$, (d) $32 \mathrm{~m}$, (e) $48 \mathrm{~m}$, and (f) $64 \mathrm{~m}$ for an IC train $(198 \mathrm{~km} / \mathrm{h})$, based on a predicted line source transfer mobility level determined with source points at the soil's surface adjacent to the track (thick black line), numerical prediction (thin black line), and measured bounds for similar train speeds (dark shaded region) and adjacent receiver locations (light shaded region). 
obtained from the passage of InterCity trains. Both numerical predictions and field measurements indicate that a strong dependence of the force density on receiver location exists, with differences of $10 \mathrm{~dB}$ commonly observed between force density values determined using receiver points at $6 \mathrm{~m}$ and $64 \mathrm{~m}$.

\section{Acknowledgements}

The first author is a postdoctoral fellow of the Research Foundation Flanders (FWO). This work was conducted while the second author was a PhD Fellow of the Research Foundation Flanders (FWO). The support of FWO is gratefully acknowledged.

\section{References}

[1] C. Hanson, D. Towers, L. Meister, Transit noise and vibration impact assessment, Report FTA-VA-90-1003-06, U.S. Department of Transportation, Federal Transit Administration, Office of Planning and Environment, 2006.

[2] A. Metrikine, K. Popp, Steady-state vibrations of an elastic beam on a visco-elastic layer under moving load, Archive of Applied Mechanics 70 (2000) 399-408.

[3] X. Sheng, C. Jones, M. Petyt, Ground vibration generated by a load moving along a railway track, Journal of Sound and Vibration 228 (1999) 129-156.

[4] N. Triepaischajonsak, D. Thompson, A hybrid modelling approach for predicting ground vibration from trains, Journal of Sound and Vibration 335 (2015) 147-173.

[5] Y. Yang, H. Hung, Wave propagation for train-induced vibrations, World Scientific, Taipei, 2009.

[6] S. François, M. Schevenels, G. Lombaert, P. Galvín, G. Degrande, A 2.5D coupled FE-BE methodology for the dynamic interaction between longitudinally invariant structures and a layered halfspace, Computer Methods in Applied Mechanics and Engineering 199 (2010) 1536-1548.

[7] R. Paolucci, D. Spinelli, Ground motion induced by train passage, ASCE Journal of Engineering Mechanics 132 (2006) 201-210.

[8] S. Jones, K. Kuo, M. Hussein, H. Hunt, Prediction uncertainties and inaccuracies resulting from common assumptions in modelling vibration from underground railways, Journal of Rail and Rapid Transit 226 (2012) 501-512.

[9] K. Kuo, H. Hunt, M. Hussein, The effect of a twin tunnel on the propagation of ground-borne vibration from an underground railway, Journal of Sound and Vibration 330 (2011) 6203-6222.

[10] H. Verbraken, Prediction of railway induced vibration by means of numerical, empirical, and hybrid methods, Ph.D. thesis, Department of Civil Engineering, KU Leuven, 2013.

[11] D. Thompson, Railway noise and vibration: mechanisms, modelling, and means of control, Elsevier, Oxford, 2009.

[12] G. Lombaert, G. Degrande, S. François, D. Thompson, Ground-borne vibration due to railway traffic, in: J. Nielsen, D. Anderson, P. de Vos, P.-E. Gautier, M. Iida, J. Nelson, T. Tielkes, D. Thompson, D. Towers (Eds.), Proceedings of the 11th International Workshop on Railway Noise IWRN11, Uddevalla, Sweden, pp. 266-301. Invited state of the art paper.

[13] G. Lombaert, G. Degrande, Ground-borne vibration due to static and dynamic axle loads of InterCity and high speed trains, Journal of Sound and Vibration 319 (2009) 1036-1066.

[14] M. Schevenels, S. François, G. Degrande, EDT: An ElastoDynamics Toolbox for MATLAB, Computers \& Geosciences 35 (2009) 1752-1754.

[15] S. Badsar, M. Schevenels, W. Haegeman, G. Degrande, Determination of the damping ratio in the soil from SASW tests using the half-power bandwidth method, Geophysical Journal International 182 (2010) 1493-1508.

[16] M. Schevenels, G. Lombaert, G. Degrande, Determination of the dynamic soil properties by refracted P-wave and surface wave characterization at a site in Lincent (Belgium), Report BWM-2011-17, Department of Civil Engineering, KU Leuven, 2011.

[17] G. Lombaert, G. Degrande, J. Kogut, S. François, The experimental validation of a numerical model for the prediction of railway induced vibrations, Journal of Sound and Vibration 297 (2006) 512-535.

[18] A. Hamid, T. Yang, Analytical description of track-geometry vibrations, Transportation Research Record 838 (1981) 19-26.

[19] H. Hunt, M. Hussein, Vibration from railways: can we achieve better than $+/-10$ dB prediction accuracy?, in: 14th International Congress on Sound and Vibration, Cairns, Australia.

[20] C. Hanson, D. Towers, L. Meister, High-speed ground transportation noise and vibration impact assessment, HMMH Report 293630-4, U.S. Department of Transportation, Federal Railroad Administration, Office of Railroad Development, 2005.

[21] H. Kuppelwieser, A. Ziegler, A tool for predicting vibration and structure-borne noise immissions caused by railways, Journal of Sound and Vibration 193 (1996) 261-267.

[22] C. Madshus, B. Bessason, L. Hårvik, Prediction model for low frequency vibration from high speed railways on soft ground, Journal of Sound and Vibration 193 (1996) 195-203.

[23] R. Hood, R. Greer, M. Breslin, P. Williams, The calculation and assessment of ground-borne noise and perceptible vibration from trains in tunnels, Journal of Sound and Vibration 193 (1996) 215-225.

[24] ISO 14837-1:2005 Mechanical vibration - Ground-borne noise and vibration arising from rail systems - Part 1: General guidance, International Organization for Standardization, 2005. 
[25] E. Bovey, Development of an impact method to determine the vibration transfer characteristics of railway installations, Journal of Sound and Vibration 87 (1983) 357-370.

[26] J. Nelson, H. Saurenman, A prediction procedure for rail transportation groundborne noise and vibration, Transportation Research Record 1143 (1987) 26-35.

[27] H. Verbraken, G. Lombaert, G. Degrande, Verification of an empirical prediction method for railway induced vibrations by means of numerical simulations, Journal of Sound and Vibration 330 (2011) 1692-1703.

[28] R. Woods, Screening of surface waves in soils, Journal of the Soil Mechanics and Foundation Division, Proceedings of the ASCE 94 (1968) 951-979.

[29] K. Massarsch, Vibration isolation using gas-filled cushions, in: Proceedings of the Geo-Frontiers 2005 Congress, American Society of Civil Engineers, Austin, Texas, 2005.

[30] S. Kattis, D. Polyzos, D. Beskos, Vibration isolation by a row of piles using a 3-D frequency domain BEM, International Journal for Numerical Methods in Engineering 46 (1999) 713-728.

[31] H. Takemiya, A. Fujiwara, Wave propagation/impediment in a stratum and wave impeding block (WIB) measured for SSI response reduction, Soil Dynamics and Earthquake Engineering 13 (1994) 49-61. 